\title{
The Evo-Eco Approach to Behaviour Change
}

\author{
Robert Aunger and Valerie Curtis \\ Hygiene Centre \\ Environmental Health Group \\ London School of Hygiene and Tropical Medicine \\ Keppel St., London WC15 7HT
}

\section{Abstract}

\begin{abstract}
We introduce a new approach to behaviour change called 'Evo-Eco' because of its intellectual roots in evolutionary biology and ecological psychology. This approach is based on the inference that behaviour evolved as a system designed through evolutionary history to provide adaptive responses to rapidly changing or complex environmental conditions. A need for behaviour change should therefore arise when individuals fail to learn appropriately from experience, due to some mismatch between environmental stimuli and learning mechanisms, leading to inappropriate behaviour. The approach therefore begins from a well-established model of how agents typically learn from experience of particular environmental circumstances the reinforcement learning model. This basic model is then expanded to determine in greater detail what kinds of learning failures can occur. Consideration of findings from the sciences relevant to components of the learning model - ranging from evolutionary biology, to ecology and psychology - leads to the development of this new model of behaviour change, which also serves as a theoretically justified checklist of factors for practitioners to examine during program development. We also report that the approach has been used to develop effective public health programs involving behaviour change, as well as to novel predictions about behavioural causes (i.e., placement within a routine) which have proved to impact on the ability to change a behaviour. We therefore hope that the Evo-Eco approach will be used by public health workers and, more generally, by (social) marketers to devise more effective campaigns, by policy-makers to improve general well-being, and by the general public as inspiration for their own self-help projects.
\end{abstract}

\section{Introduction}

Behaviour change has recently come to be recognized as an important objective of public policy, marketing, education, business management (leadership), health promotion, city planning (to improve the design of buildings and public spaces to promote health or interaction), sport psychology (to improve performance), website design (to improve the 'user experience'), and selfhelp efforts (e.g., financial goal achievement). It is being heralded as a policy cure-all in the halls of government, as a way to improve student learning in schools, or to make marketing more scientific, and as a necessary lynch-pin of successful programs in public health. Behaviour change is thus a 'hot topic' in many fields.

The concept of behaviour change implies that preferable courses of action are perceived as possible, but tend not to occur. It is often seen as being 'hard'. Failed New Year's resolutions and dieting regimes are given as examples. However, changes in behaviour are happening everywhere, all the time. Social life has changed considerably: we now live in megalopolises, fly 
from continent to continent. Some people now cope with multiple shifts in their jobs over their career (whereas people used to be born and die in the same profession, or even just all to have the same profession, such as farmer), and participate in numerous social networks (e.g., church members, bridge club, work groups, sports teams, hobby clubs), rather than just being kin or neighbours. People have learned to deal with novel institutions: children spend half their daily lives in school; many people now people use coins or pieces of paper to trade for things, keep some of their money in a bank, or use 'virtual money' in the form of credit cards or Paypal accounts. People take regular baths, give birth in hospitals, drive cars, wear glasses or hearing aids, and fling dirty dishes into a dishwasher. In 1985, no one could telephone others while they were 'on the run'; twenty-five years later, many people in the poorest villages in Africa are using mobile phones. The internet has disrupted many old behaviours since its introduction around 1995: interpersonal communication (letter-writing to email to twitter), consumption patterns (physical to on-line shopping), even reading books (on screens rather than in printed form). In fact, for this increasingly important kind of behaviour change - learning to live with new technologies - the rate of adoption is becoming faster with time: mobile phones have become endemic in only a few years, whereas regular showering took many years to become popular (http://www.karlhartig.com/chart/techhouse.pdf) So in many ways, human psychology is exquisitely tuned to producing the most appropriate response to what a changing environment throws up. The rate at which populations can change their behaviour is actually increasing.

This is possible because human behaviour is highly flexible; it responds rapidly to changes in the environment. Not all organisms can do this (e.g., can't respond to rapid environmental changes, or have narrow diet or niche), and as a result may go extinct. (Martínez - Meyer, Townsend Peterson, \& Hargrove, 2004) Even complex behaviours can be programmed by genes if the environment remains stable long enough. However, in stochastic environments, the optimal course of action can change more rapidly than genetic changes can track. Further, if many tasks must be achieved through behaviour, competition and conflict can arise between goals, requiring contextualized switching between tasks, which also means the optimal course of behaviour at a given moment can be different. So species such as animals that depend on behaviour for solving many tasks can also run into decision-making problems.

Adaptive behaviour in complex or stochastic environments thus requires flexibility. The ability to reliably produce quick, responsive kinds of interaction with stochastic environments was enabled by the development of a nervous system, which had the ability to detect and classify the situation, as well to store information that could be of benefit in selecting appropriate responses when encountering similar conditions later - that is, the ability to learn from experience. (R Aunger \& Curtis, accepted; Freeman, 1999; Sterelny, 2003) The nervous system is thus able, first, to direct complex movements of various body parts relatively quickly, and second, to store information acquired through feedback from behavioural choices in the form of memory. Only animals have nervous systems. It is the combination of rapid behavioural learning, in response to environmental changes, enabled by nervous systems, that characterizes the animal mega-adaptation. Complex behaviour - such as humans exhibit - thus has the purpose of keeping bodies alive and reproducing through rapid, flexible self-propelled bodily movement, producing a functional interaction between an animal and its environment. (R Aunger \& Curtis, accepted; Millikan, 2000; Plotkin, 1988; Tinbergen, 1963)

Animals have had to succeed under conditions that require a high degree of flexibility, as their environments tend to fluctuate rapidly. (Huey, Hertz, \& Sinervo, 2003; Wcislo, 1989; Wyles, Kunkel, \& Wilson, 1983) Indeed, human evolution has been characterized by particularly violent and shifting selection pressures, as a result of environmental fluctuations, particularly over the last 
10,000 years. (Quartz, 2001; Richerson \& Boyd, 2005) This history has left its mark in terms of a large brain for coping with these rapid changes. Indeed, we can be said to have evolved particularly large brains to cope with recurrent environmental variability during our evolution. (Potts, 2012) Further, as discussed above, environmental changes have only increased in speed with more recent technological developments. So we are becoming more and more reliant on producing adaptively plastic or flexible responses to changing environmental conditions.

This evolutionary perspective suggests that, if there is a need to change behavioural responses to particular situations, it must be due to some inability to adapt appropriately to environmental change through the usual evolutionary mechanisms. Indeed, we will argue that the need to change behaviour has arisen because environmental conditions exist that prohibit effective learning and hence performance of the appropriate behavioural choice. We will show below that, under certain conditions, learning does not work adaptively, so that particular kinds of discrepancies can arise between what the environment throws up, and how psychological mechanisms can gain knowledge from experience of those situations. Further, those situations tend to be the ones in which people seek to induce changes in behaviour - either in themselves, or others.

This paper presents the case for a new approach to behaviour change founded on this insight about learning difficulties. In subsequent sections, the approach will be presented in several different forms - as a model of behaviour change (couched in terms of a general learning model), as a model of behavior determination (more consistent with how other models of behaviour change are presented), and as a model of how behaviour has itself developed over evolutionary history, which provides a checklist of issues for behaviour change specialists to consider when developing interventions. These presentations will require the development of several different perspectives on the general problem of behaviour change and an investigation of the best available science for indicators as to the contents of the various model components. In the process, we show how the approach accounts for the types of problems which become public health problems in the first place, and why they require behaviour change. We discuss projects where this approach has been used successfully to change recalcitrant behaviour, and conclude with an exhortation to use the approach in future behaviour change efforts.

\section{Failures to learn}

To better understand how learning can fail to happen appropriately, we here model how learning is supposed to work, so that we can pinpoint the ways in which the system can break down.

Making optimal choices about how to behave can be a difficult proposition, partly because of the 'credit assignment problem' (Richard S Sutton, 1984): Outcomes in complex situations may depend on a series of actions, only the last of which provides a reward or punishment. This means that feedback can be delayed, and it can be difficult to determine where the decision-making process 'went wrong'. Think of a chess game, in which you play for 50 moves and lose - how can you learn which move doomed you to failure in the end - the $3^{\text {rd }}$ move, the $23^{\text {rd }}$, or the $43^{\text {rd }}$ ?

Reinforcement learning $(\mathrm{RL})$ is an algorithm that can solve this problem. (Richard S Sutton \& Barto, 1998) Although originally developed in computer science to study machine learning and the optimum control of production processes, (Richard S Sutton \& Barto, 1998) it has also been widely used in psychology and neuroscience. RL is currently the best-established computational model of how autonomous agents such as animals and robots acquire information through experience with their environment. Indeed, RL has been independently validated, using different kinds of criteria and standards of practice, in four very different fields: control theory/operations research, artificial 
Reinforcement learning is designed to describe the everyday processes by which agents learn, via trial and error, to act upon a changing environment so as to maximize a future stream of rewards, based on only partial knowledge of their world. RL explains how animals or robots can adapt their behavior to varying contingencies by repeatedly updating their estimates of the rewarding value of alternative actions, thanks to feedback received from the environment as a consequence of action. This can lead, over time, to different responses to the same stimulus - behaviour change. Thus, reinforcement learning suggests that learning is about correcting errors. (Rescorla \& Wagner, 1972) Hence, if learning fails, errors persist - potentially requiring an intervention to change behaviour.

From this perspective, the agent's job is to identify a policy that maps perceived states of the world to actions which maximizes some measure of long-term reinforcement. Reinforcement signals can be computed at various points during the time over which a goal is being pursued. Learning occurs whenever there are discrepancies between the level of reward that is expected from a behaviour and that actually received after it has been executed. A 'temporal difference error' proportional to the difference between the time at which the behaviour was selected, and the point at which feedback comes from the environment) alerts the system to situations in which the change in value of the current state from the previous state (brought about through behaviour) are significantly different from what was expected (e.g., not as much progress toward achievement of the goal as believed). (Schultz, 2000; Richard S Sutton \& Barto, 1998) This allows the brain to adjust expected levels of reward during in the process of goal achievement, and hence produce adaptive responses to changing circumstances. (Waelti, Dickinson, \& Schultz, 2001)

Reinforcement learning is a form of operant or instrumental conditioning - the kind of learning associated with performing a behaviour, rather than simply being exposed to, and learning about, relationships between environmental stimuli (i.e., classical conditioning). ${ }^{1}$ Further, reinforcement learning involves variation (generated behavioural options) and selection mechanisms (i.e., action selection among options). Also, it includes memory and learning facilities, which start from where the last iteration stopped, so there is an inheritance mechanism for informational states as well. These qualities make reinforcement learning an evolutionary process. (Fernando, Szathmáry, \& Husbands, 2012; Moriarty, Schultz, \& Grefenstette, 1999; Singh, Lewis, Barto, \& Sorg, 2010; Whiteson \& Stone, 2006) (Variation, selection and inheritance are the basic elements of the 'Darwinian algorithm' (Godfrey-Smith, 2007; Lewontin, 1970).) What this suggests is that organic selection in populations of organisms is mimicked by the operation of the nervous system, where evolution takes place within the lifetimes of organisms in terms of how their behaviour is selected and produced. In effect, the fundamental mechanisms of biology (natural selection) and psychology (behaviour production) can be shown to be computationally equivalent. (McDowell, 2010) This gives reinforcement learning a very strong foundation, by falling within central theoretical and empirical traditions in both biology and psychology.

The model adopted in this paper to understand behaviour change - which embodies a version of reinforcement learning - can be seen in Figure 1 (based on Figure 1 from (Singh et al., 2010)). This representation can be thought of as two causal loops - since the brain lies within body, and the body within the environment - but is presented as spatially independent loops for pictorial clarity. (An embedded version is presented later.) 
Figure 1: The Evo-Eco Process Model

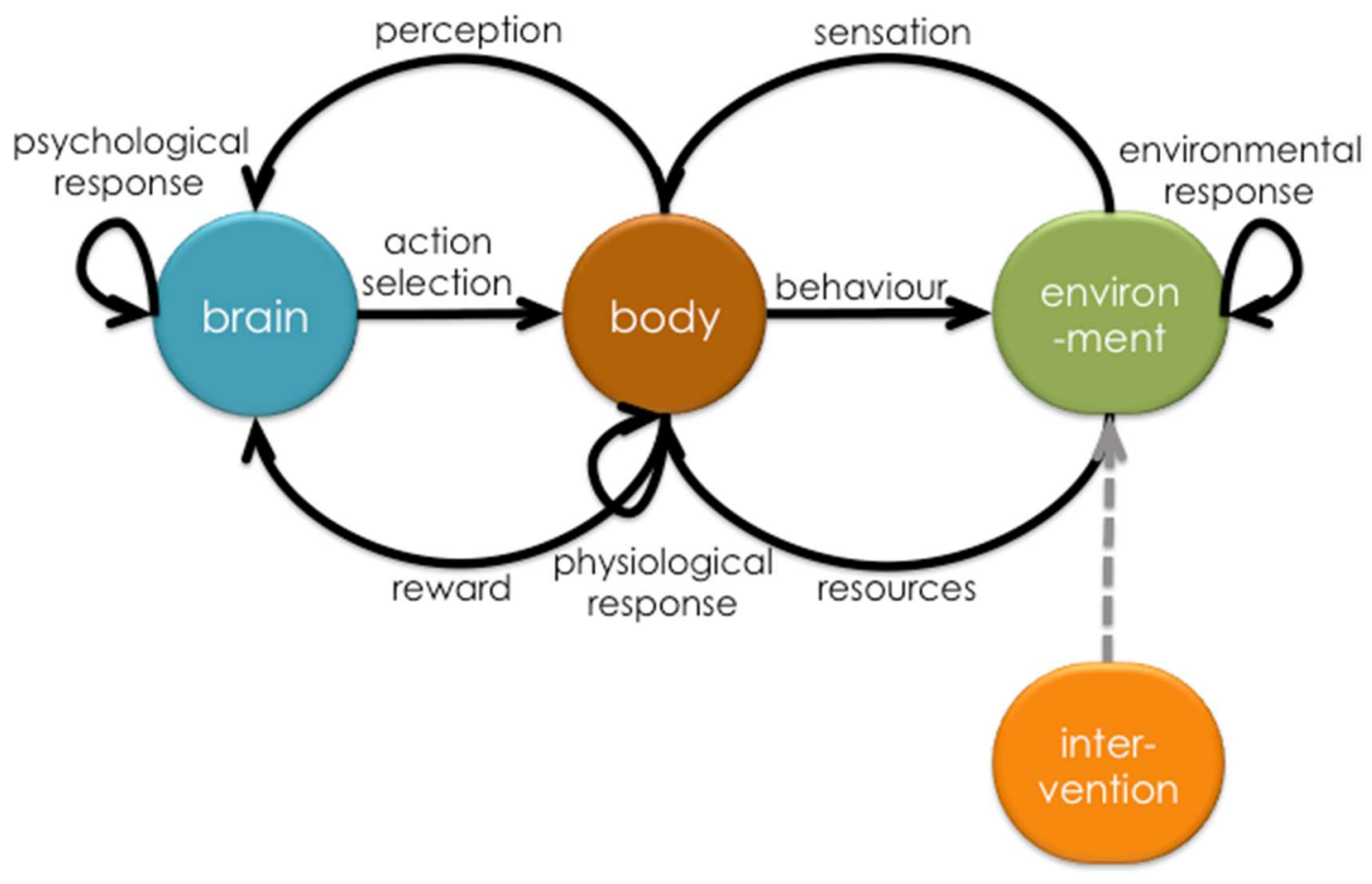

The basic reinforcement learning model has been augmented to make it more realistic in ecological terms. This is necessary as the reinforcement learning literature was originally purely computational (or information-theoretic) in nature. In particular, the body is given physical reality by adding physiological processes of metabolism and arousal, while the environment is allowed to provide the body with resources such as food and social companionship. The environment is also granted endogenous responses, because it includes other agents like animals as well as other humans, and so will respond adaptively to behavioural stimulation by the focal individual. Further, the brain also responds to rewards and perceived changes to the environment by updating its model of the world (learning) and storing this information for later use (memory). ${ }^{2}$

According to the model, a cycle of behaviour causation begins in the brain, which, based on current knowledge of the state of the world, uses the $\mathrm{RL}$ algorithm to compute the value of various behavioural options. Based on these values, an action selection process picks the highest valued option, and instructs the motor cortex to perform the selected 'policy' (or action sequence), which is stored as the optimal option for that situation (for future use). These instructions cause a metabolic response and arousal in the body, which produces behaviour, or interaction between the body and its environment. (Odling-Smee, Laland, \& Feldman, 2003) Behaviour results in a change to the state of the environment (e.g., chasing a prey causes a change in location of one's body in relation to the physical surroundings), which can cause endogenous reactions by the environment (e.g., a prey avoids capture by engaging in independent movement). The consequences of behaviour are thus a combination of the activity of the body and the environmental response. This outcome is what is sensed by the body, as the first sort of feedback. Resources can also be acquired through the behaviour (e.g., meat through capture of the prey). Consumption or use of the resources provides changes to the peripheral nervous system, transmitted to the brain, which also converts the sensations from the peripheral nervous system into perceptions of changes in the environment and the body's internal states. On this basis, the brain calculates a reward as the information from perception and resources acquired minus the metabolic/arousal costs of 
producing the behaviour in the first place. Rewards are subjective, or psychological - positive if the action resulted in an environmental change consistent with the animal's goal (e.g., chasing a prey resulted in the prey being captured), or negative if not. Learning and memory then take place as endogenous changes in the brain. The brain allows the animal to associate the perceived changes produced in the environment by the behaviour with the resulting reward (positive or negative) from prior action selection - an instance of reinforcement learning.

Note that the process runs repeatedly: that is, after learning is complete, in the next time-frame, the cycle begins anew, with the animal selecting another action, given the new state of the environment, and getting feedback in the form of a reward and perception of new changes in the environment, resulting from the new behaviour. Thanks to reinforcement learning, actions that lead to positive rewards tend to be repeated when similar circumstances present themselves again. Over time, the animal learns to perform actions that tend to result in high payoffs - as expected if behaviour is an adaptation to produce effective responses to a variety of environmental conditions. Indeed, robots programmed with reinforcement learning algorithms come to perform behavioural patterns consistent with expectations from evolutionary theories about behaviour. For example, teams of robots using different strategies allocate their energy in 'food quests' in ways consistent with competition between species in the same niche from optimal foraging theory. (Ulam \& Balch, 200?)

This augmented model we call the Evo-Eco Process Model, due to its roots in evolutionary theory and its attention to ecological factors. ${ }^{3}$ (Figure 1 is called a 'process model' to distinguish it from another representation of the approach to follow later.) The model also includes the possibility of an intervention, as the primary means of inducing behaviour change. An intervention is typically itself a form of behaviour by an outside party (e.g., a message spoken to a friend, or putting a billboard on the side of a bus), but this behaviour may have already occurred (e.g., in the form of an environmental modification with which the target behaviour will interact), or only be planned (with the intention to see how the intervention will influence other model elements), or be unnecessary (as in the case of a self-induced decision to lose weight through a self-help program) - hence the link is represented as a dotted line in the model.

With its concentration on feedback loops between the brain, body and environment, and the possibility of interjecting some novel element into the cycle, the Evo-Eco Process Model has structural similarities to the existing approaches to behaviour change (as opposed to behaviour determination): Social Regulation Theory (Carver \& Scheier, 1998), the Antecedent-BehaviourConsequence (or ABC) model used in Applied Behavioural Analysis, (Martin \& Pear, 2007) and the Transtheoretical approach. (Prochaska \& DiClemente, 1983) They are all composed of positive feedback loops (see Figure 2). ${ }^{4}$ In effect, no model of change has been developed that doesn't involve an intervention at some point in the body-environmental interaction - a modification which, once induced, then feeds forward to the other model components. This suggests that there is something fundamental about seeing change in cyclical terms - a point with which our approach is consistent. 


\section{Figure 2: Behaviour Change Models}

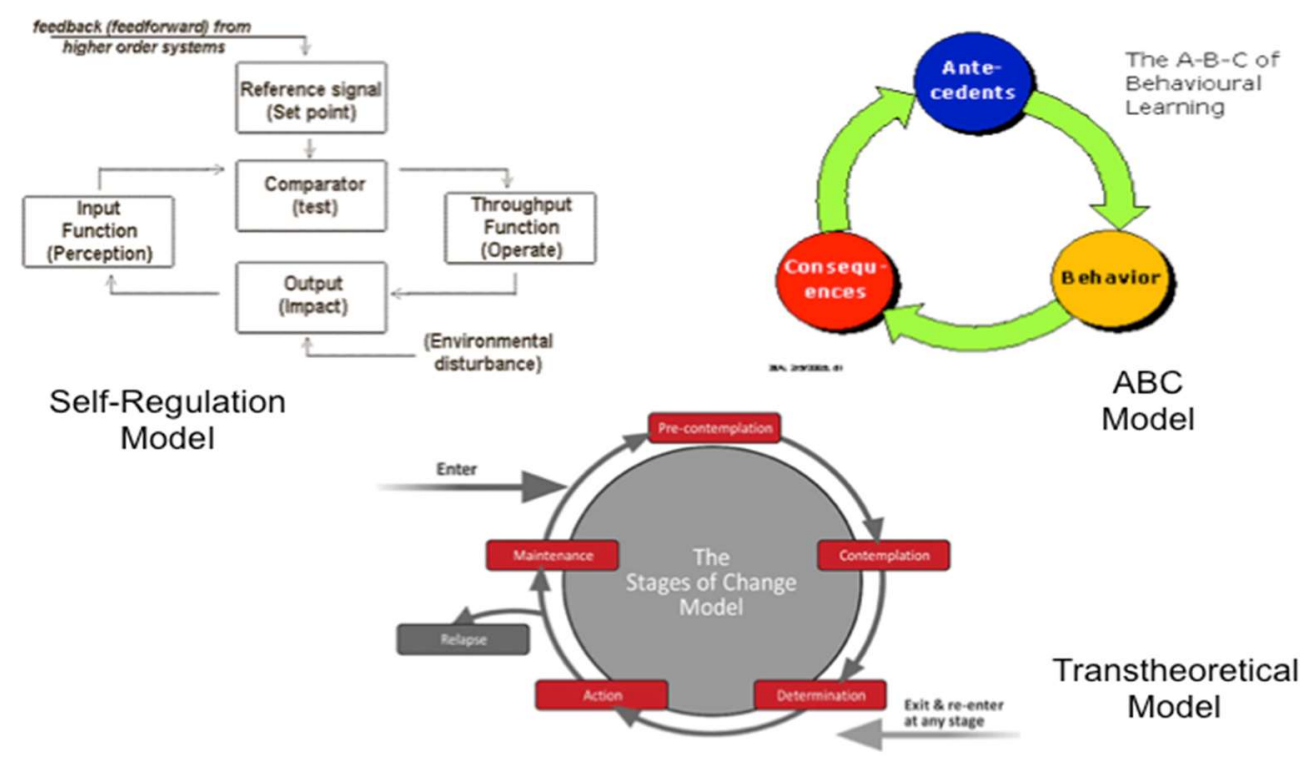

Learning is not the only brain function which has been characterised as using error correction as a mechanism. Error correction has also been demonstrated to characterize the following specific domains: perception (as minimization of 'prediction coding') (Rao \& Ballard, 1999), action selection (as the 'neuroeconomic principle' to maximize expected utility) (Montague \& Berns, 2002), memory (as world model updating to minimize 'surprisal') (K. Friston, 2010), and motor control (as 'forward modeling' to minimize the discrepancy between expected and perceived body position). (Shadmehr, Smith, \& Krakauer, 2010) As a result, there is a growing consensus that error correction should be recognized as a mechanism characteristic of the brain's operation as a whole. Authors reaching this conclusion have been called this perspective the 'Bayesian brain' (Doya, 2007), the 'predictive brain' (Bubic, Von Cramon, \& Schubotz, 2010), and the 'proactive brain' (Bar, 2007), and the global mechanism itself the 'free energy principle', (K. J. Friston \& Stephan, 2007) 'failure modes' (Redish, 2013), and 'nested intelligence'. (Hawkins \& Blakeslee, 2004)

Only a few behaviours do not participate in the normal error-correction-based learning process, but these are the ones that everyone focuses on, as they cause problems, or are otherwise lessthan-optimal from some perspective (e.g., not enough sales or market share). The 'behaviour change problem' is therefore one of overcoming learning difficulties. From this perspective, the problem is that some behaviours are persistently resistant to change. People know they should do their home-work, clean house, save money for retirement, quit smoking, eat healthier diets and exercise more, but find it difficult to actually do so. Typically these behaviours affect large groups of people, and so become problematic, both at an individual and public level. It is only in these few cases that behaviour has 'gone wrong', and yet can't be modified effectively. So behaviour change isn't hard per se, it's only hard when you notice there's a problem, because the desired change isn't happening.

Overcoming error correction failures means knowing more about how learning normally occurs, to understand how it can go wrong. The Evo-Eco Approach is the result of an effort to design an approach to behaviour change that takes its inspiration from this insight. 


\section{The Evo-Eco Approach}

To properly assist those seeking to change behaviour, we need to develop our model of reinforcement learning so that it can address specific learning failures and show us how to change the flow of these different processes into desired channels. In effect, each of the Evo-Eco Model components need to be 'opened up' to see what kinds of factors it brings into play - how exactly it might help funnel behaviour into functional channels, and lead to learning successes in specific kinds of circumstances. The foundation of the approach is a specific learning model: the reinforcement learning model, which describes how the brain changes as a result of interaction with the environment via the body within which it resides (hence the spatial configuration of the components in Figure 3, the component-based version of the Evo-Eco model, which places the brain inside a body which is, in turn, in an environment). The basic elements of the model are

- the environment, which presents some challenge to the individual

- the brain, which produces potential responses to that challenge, and

- the body, which engages in interactions with the environment (i.e., produces behaviour) that meaningfully changes that environment.

Next, then, we consider each of these components at greater depth, bringing to bear, in each case, the latest relevant science to better understand what content exists within that element of the model. We will organize this discussion, however, in evolutionary terms, showing how the content of each component has developed at crucial intervals in the history of animals leading to humans. This is because the means by which behaviour is produced has itself changed over the course of evolutionary history. These different ways remain in place within the human brain as separate mechanisms of behaviour production, (R Aunger \& Curtis, accepted) but an understanding of origins will help when it comes to trying to change behaviour.

\section{Brain (including psychological responses)}

The first component to be discussed is the brain. The most important thing to note here is that the brain is an evolved organ adapted to produce behaviour that promotes survival and reproduction of its body. (R Aunger \& Curtis, accepted; Churchland \& Sejnowski, 1992; Freeman, 1999; Hebb, 1949; Llinas, 2002; Swanson, 2003) As such, it has a long evolutionary history during which it has acquired a variety of adaptations. Primary among these are mechanisms for controlling behaviour. Three levels of control have evolved in human brains, each of which can be isolated neuroscientifically. (N.D. Daw, Gershman, Seymour, Dayan, \& Dolan, 2011; N. D. Daw, Niv, \& Dayan, 2005; Dayan, Niv, Seymour, \& D Daw, 2006; Edmund T Rolls, 1999; Wunderlich, Dayan, \& Dolan, 2012) We will take the points at which these different control mechanisms have evolved as our crucial steps in the development of behaviour production in humans. Responses to behaviour take the form of learning and memory mechanisms associated with each level of control.

The baseline for behavioural control comes when early invertebrates such as jellyfish and worms appeared (about 600 million years ago). The first control mechanism to have evolved, and which remains characteristic of invertebrates, was simple reactions to environmental stimuli that likely represented opportunities or threats. This is Pavlovian decision-making, which entails the release of species-specific approach and avoidance reactions in response to unconditioned or conditioned stimuli (i.e., reflexes). (Pavlov, 1927) So, recognition of a potential food item would inspire 
approach among these early animal species, and contact with a poison would inspire recoil. (Abramson, 1994; Krasne \& Glanzman, 1995)

\section{Figure 3: The Evo-Eco Component Model}

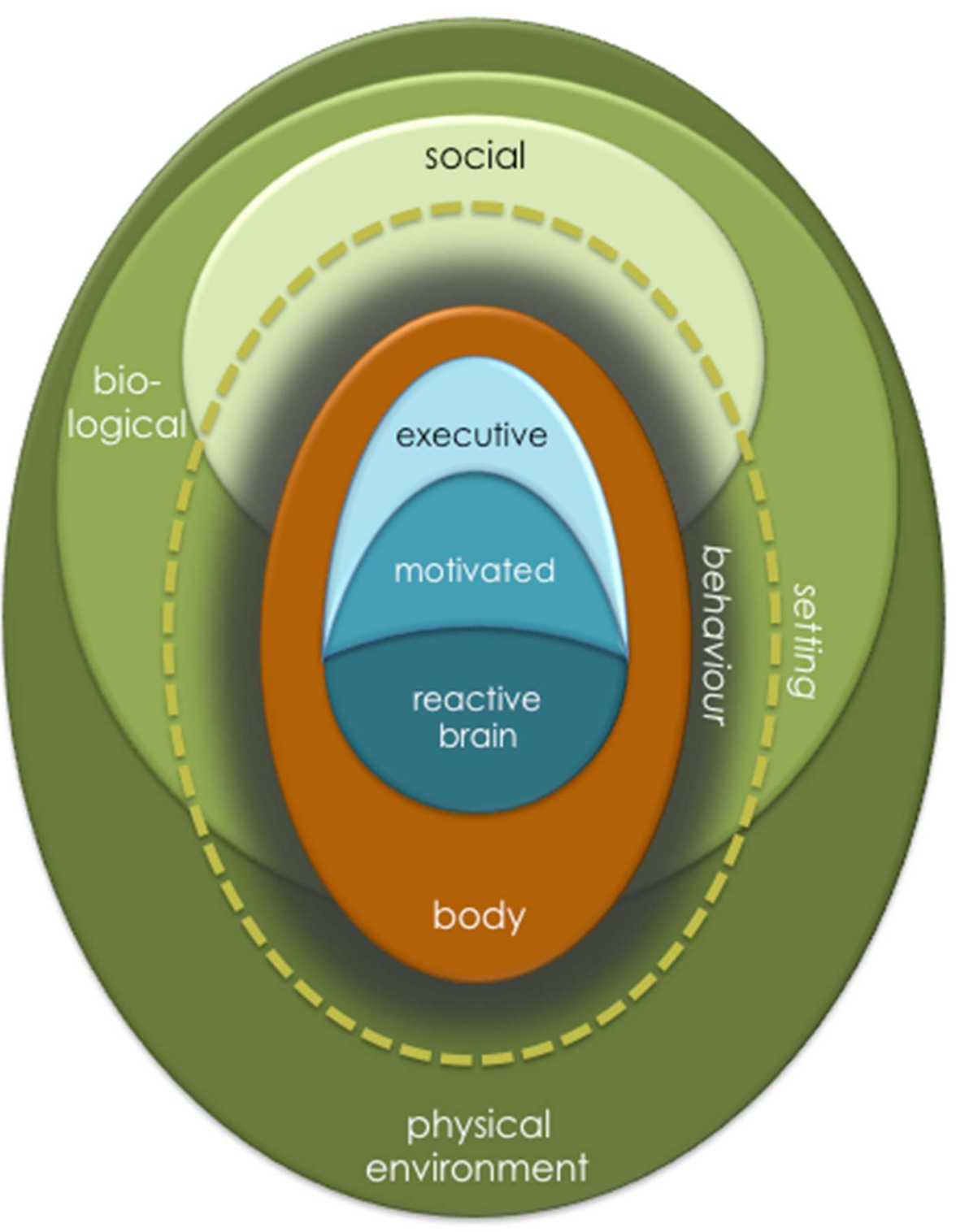

At this level of relatively simple nervous systems, learning is restricted to basic forms of conditioning, or acquiring associations between stimuli, or between stimuli and behavioural responses. (Mackintosh, 1985; Staddon, 2003) The result is incremental learning of relatively inflexible stimulus-action relationships that are released upon exposure to certain environmental stimuli. This reactive-level learning is based on the Hebbian rule whereby neurons that 'fire together, wire together', (Hebb, 1949) such that associations become stronger through experience. For example, in fear conditioning, an animal acquires avoidance responses to a previously neutral stimulus when it becomes paired with an aversive stimulus, such as a shock or loud noise. Reactive level learning is called 'classical conditioning' by animal behaviour researchers. It 
involves attaching a new link to an existing cluster of knowledge (e.g., faeces tastes awful, so the animal will recognize faeces next time as something to avoid tasting). It is Pavlovian in the sense that learning to associate an unconditioned stimulus (bad taste) with a conditioned one (the sight of faeces). Such learning is also predictive in the sense that faeces will now be expected to taste bad whenever it comes into view, even without the experience - a learned aversion. (Dayan et al., 2006) A special form of Pavlovian learning is 'evolutionary prepared' learning mechanisms such as the Garcia effect, a mechanism that trains the body to avoid poisonous substances after only a single exposure, due to its significance for survival. (Garcia \& Koelling, 1966) These acquired (rather than innate) automatisms are commonly called 'habits'. (Lally, Jaarsveld, Potts, \& Wardle, 2009; Ouellette \& Wood, 1998)

The first novelty in behaviour production occurred with the arrival of mammals around 200 million years ago. The psychological adaptation characteristic of mammals is motivational control for goal achievement. (Butler, 2001; Northcutt \& Kaas, 1995; Streidter, 2005; Willis, 1985) Goals are mentally represented end-states that are calculated to be achieved through some sequence of behaviours. The existence of goals enabled new forms of learning because satisfying the goal can be accompanied by psychological rewards that promote the same behaviour the next time the situation arises. This is achieved by associating the positive outcome with whatever mental mechanisms produced the behaviour in the first place (i.e., evaluative learning). For example, signals from peripheral parts of the body can be sent to the brain to indicate the current status of various tissues and organs (e.g., hunger), that instigate searches for an improved state (e.g., food consumption). In this way, animals can learn a potentially arbitrary policy to obtain rewards or avoid punishments (e.g., a rat can learn to press a lever in one location so that food becomes available in another location). Learning can now rely on mental representations, or clusters of associations, so that associations between clusters constitutes a higher-order form of associative learning. Goal-states can come to be associated with the characteristics of events that lead to occurrence of the desired end-state; these characteristics make the goal more or less salient (e.g., water-holes may become associated with capture of prey if prey are often successfully encountered at water-holes). (B W Balleine \& Dickinson, 1998; Berridge \& Robinson, 2003) This style of learning will be called affective, as it is designed to help animals achieve rewards via goal satisfaction. It uses the temporal difference error rule discovered by reinforcement learning researchers to associate the animal's current state with its degree of progress toward the current goal, working sometimes with respect to mentally represented states that only have psychological value, not resource value (i.e., a state that is leading the animal to, or correlated with, achievements of a state that will provide resources).

Emotional memory is associated with affective learning. It is a facility for storing affectivelycharged experiences and associations, particularly those representing significant opportunities or threats, and hence likely to produce large rewards or punishments. (Burke, Heuer, \& Reisberg, 1992; Kensinger \& Corkin, 2004; Valentin, Dickinson, \& O’Doherty, 2007)

Also associated with the development of a reward system and goal representation are motives, or psychological adaptations for achieving particular kinds of goals. These goals are associated with solving elementary evolutionary tasks such as finding food or a mate. Which motives a species can be expected to exhibit are determined by the niche in which the species lives, which in turn define the evolutionary problems it must solve to flourish and reproduce. (R Aunger \& Curtis, accepted) All animals must find food, many must find a mate (if they depend on sexual reproduction), fewer must climb the social ladder of status (because only a few animals are social, much less have social hierarchies). The means by which each of these niche-based tasks is solved depend on the species' evolutionary history (e.g., some species solve the food problem by 
scavenging, others by being predators). The various human motives will be described below, as their roles become relevant.

When primates evolved about 65 million years ago, a third level of control arose, called 'executive' control, based on the ability to run through imagined scenarios of future outcomes. This deliberative level of decision-making entails search and evaluation of action options through a representation of the causal structure of the world. (Tolman, 1948) This can be thought of as occurring through recursive test-operation-test-exit units operating on hierarchical mental modules (Kopp, 2012) - a straight-forward application of the cybernetic principle on which reinforcement learning is built.

In reinforcement learning terms, executive level learning is instantiated as an actor-critic model (a member of the class of 'model-based' learning mechanisms). (Richard S Sutton, 1984) The 'actor' is the map (or database of world knowledge), which gets feedback from the reward system, so it learns new facts about the world (e.g., where food can be found, or more declarative memory items), while the 'critic' (equivalent to the temporal difference-based system, which executive level mechanisms makes use of) updates the expected value of the just-performed behaviour, based on the same reward feedback signal as is fed to the 'actor'. Thus, the executive level just adds the 'actor' part to the motivational system. Executive level learning is more about new memory resources than new learning mechanisms.

Learning at this level can be associated with hierarchical goals, or sub-goals that represent achievement of mid-states that reflect some conceptual or functional clustering (e.g., being the first stage of a process that results in resource acquisition, such as boiling a pot of water for tea). Goals at any level of the hierarchy are evaluated using the same temporal difference error mechanism as works at the motivational level.

Some of the processing occurring at this level bubbles into consciousness, which is a limited 'theatre' in which memory and other information is pulled together for decision-making and other tasks. (Baars, 1997) Declarative memory is again a specialized mechanism for remembering the specifics of particular experiences, such as the license plate number of the car that just hit someone on the street, or the name of a second cousin. (Eichenbaum, 2000; Tulving, 1985) Declarative memory allows humans to develop highly specific scenarios based on detailed information, and thus weigh up very complex chains of potential future actions against one another. Identity is a special form of declarative memory as a stored representation of the self that (associated with executive control). For behaviour change, another important form of memory is social norms: People have ideas (based on experience) about what other people do (descriptive norms), and what other people think they should do (prescriptive norms), which can impact on their own behaviour (through the motives to affiliate or increase status).

Thus, for each level of mental control over behaviour, there is an affiliated adaptation for the storage and recall of information specific to the control task at that level. There is also a specific mechanism for learning at each level, which at the executive level is conceptual learning. This is a recursive form of earlier learning, in that it now can work with even more deeply embedded mental representations, such as a model of the self placed within a model of the external world. Learning can also come from the conscious rehearsal of recent failures or successes, or from the rehearsal of possible future action-sequences using our strong narrative-producing mechanisms something we call reflective learning. (Joe, Ferraro, \& Schwartz, 2002; Edmund T. Rolls, 2005) 
All three behaviour determination or control systems are operating all the time, in parallel, in order not to waste experience. (Dayan, lecture) Having multiple decision-making systems allows the brain to make use of controllers with different advantages. Model-based (forward search) is a good policy when close to reward (not many steps to search) and there is little time for training; modelfree (rely on cached knowledge) is more appropriate when the agent has lots of experience and the distance to reward is not too important. Reactive level determination is best when there is little margin for error (e.g., the consquences of a wrong decision impact on morbidity or mortality). So a general rule is, if an animal has experienced only few trials of a particular circumstance, it should use executive level production (because it will be able to produce some estimate of the likely returns to behaviour by searching the relevant solution space); if it has more experience, it should use learned automatic responses (i.e., habits). On the other hand, if prior generations have had similar experiences, their correct responses might have been encoded in Pavlovian reactive mechanisms producing 'hard-wired' responses. (Talmi, Seymour, Dayan, \& Dolan, 2008)

Thus, with each increasing degree of sophistication over the production of behaviour, there are psychological adaptations for selecting among more and more complex sequences of behaviours, which can be put together based on information recalled from specific forms of memory that store just the kinds of information needed to construct those mental representations of future activity. But this means there is competition at any given moment between them. Thus, there must be some mechanism for integrating between them (i.e., a meta-control mechanism). There is growing evidence that they are integrated. (N. D. Daw et al., 2005; N.D. Daw \& Shohamy, 2008) The control of behavior can be shifted from one system to another through focal brain lesions, suggesting the coexistence of neurally distinct decision making systems. (B.W Balleine \& O'Dohety, 2010; A. Dickinson \& Balleine, 2002) Choice between systems is to trust the one which is more confident of its recommendation (i.e., habit when lots of experience and low uncertainty, model-based when opposite conditions), so getting expected value with uncertainty. (N. D. Daw et al., 2005)

There are significant interactions between levels of control over behaviour production and evaluation. In particular, habit formation is a specialized mechanism that progresses control through each of the three levels of control through repeated experience. (A Dickinson, 1985; Everitt \& Robbins, 2005; Yin \& Knowlton, 2006) It can begin with a conscious decision to acquire a new behaviour, progress to motivated behaviour, and, through continued learning in regular environments, end up as a practiced automatism. Over time, repeated temporal-difference learning can lead to reduced errors, at least in stable environments, until the errors are essentially eliminated, at which point the brain releases control to reactive level production (i.e., the response becomes habitual). (Pasupathy \& Miller, 2005) This is Thorndike's 'law of effect'. (Thorndike, 1901) In each step, repeated reinforcement leads to reducing the level of control necessary for continued behaviour production, ending up with fast-acting, automatic responses to environmental cues using a purely reactive level of control. (Poldrack et al., 2005) With this kind of Pavlovian control, actions are automatically elicited at the presentation of reinforcers, whether or not the actions lead to acquiring rewards or avoiding punishments. (Breland \& Breland, 1961; Dayan et al., 2006) In humans, procedural memory is an adaptation to help recall the skills necessary to execute what have become automatic behavioural responses. (Bullemer, Nissen, \& Willingham, 1989; Squire, 2004)

Other interactions between control mechanisms like this no doubt await discovery. However, these complexities can also lead to problems. Reactive, affective and reflective learning mechanisms can interact in complex ways that introduce structural constraints on learning. Interactions among these various brain structures can constrain learning in ways that lead to maladaptive outcomes, 
regardless of changes in the environment, as they have evolved to serve different ends and then been forced to work together. Alternatively, some forms of interaction between complex reinforcement learning mechanisms and environmental stimuli, or unexpected endogenous responses by the environment to behaviour, may also cause problems. Thus, kinds of difficulties that lead to a need for behaviour change can arise within the brain, or in the environment as a stimulus for learning, or in environmental responses as well. Interactions of various kinds among the elements of the Evo-Eco model (or even within a structured brain) can thus be the source of a need to change behaviour.

\section{Body (including physiological responses)}

Second is the body in which the brain resides. The body is our 'primary interface' with the environment, how we modify our surroundings, through behaviour, to better suit our needs. Two aspects of the body are important when considering how it produces behaviour. First, any body has a morphological nature - that is, its precise shape determines what sorts of movements can be undertaken. For example, the body's size in part determines how much force can be applied to environmental objects (e.g., how far a stone of a certain weight can be thrown). For example, the precise shape of the beak of the various Darwin's finches determines which feeding niche they occupy, as it determines which sorts of nuts and seeds can be successfully consumed. (Grant \& Grant, 2002) Internal body morphology is also relevant. Thus reptiles and birds produce eggs, which need specific forms of care and defense as compared to the live offspring produced by mammals. For these reasons, there tends to be a tight relationship between body morphology and a species' niche.

Once we get to humans however, each body morphology, being unique, and visible to others in the social group, also gives people an ethnic, gendered, age-grouped identity, which is stored and modified by experience in declarative memory (the kind of memory associated with executive control). Social roles are important as part of identity as well, and became individuated with the multifarious division of labour that accompanies membership in the large groups that humans live in. This identity can also include psychological aspects: cultural beliefs, traits of various kinds (such as personality and mood), and episodic memories from one's personal past (a specific form of declarative memory). These are obviously psychological in nature, but arise as a consequence of the body's unique appearance and experience. Similarly, long-term biases in the performance of behaviour (e.g., mood, personality-based traits) can also be thought of as being associated with the constancy of the body, rather than the constant turmoil of the brain, and so as having some physiological element (e.g., as reflecting general excitability). (Glenberg, 2010; Michalak et al., 2009) Skills, or the ability to perform highly practiced behaviours well, such as athletic feats or complex everyday behaviours, are also often thought of as embodied, given that they become embedded in 'muscle memory', or the peripheral nervous system. (Gallagher, 2005)

The body produces physiological changes in response to signals from the brain that action is imminent. Arousal (increasing activation of the autonomic nervous and endocrine systems, leading to increased heart rate, blood pressure and sensory awareness in the presence of a threat or opportunity in preparation for action) can be considered as part of the metabolic system from this perspective. Arousal is also a way the body prepares for goal pursuit, (Hull, 1943; James, 1884; Yerkes \& Dodson, 1908) so it can be considered an adaptation arising with mammals to 'energize' motivated action. Arousal is the body's endogenous response to information from the brain about an action having been selected. 
Second, engaging in movements such as behaviour requires physical energy, which in turn requires mobilization of the body's chemical machinery for producing kinetic energy - that is, the body's metabolism. The body thus experiences an energy drain as a consequence of engaging in behaviour; against this, it can acquire resources (e.g., through prey capture).

Causation is also reversed in the sense that the brain is impacted by residing in a body. For example, reinforcement learning can reflect embodiment, taking place specifically with reference to which parts of the body help achieve goals - that is, the algorithm can be modularized to include multiple reinforcement processes for each relevant part. For example, when actions are produced via simultaneous movement of both hands, a model suggesting left and right hands received separate reward feedback for each hand movement produced better predictions of chosen behavior than a traditional model that treated the actions as unitary, with a single value. (Gershman, Pesaran, \& Daw, 2009)

\section{Environment (including environmental responses)}

The third component of the Evo-Eco Components Model is the environment. Unfortunately, the notion of environment remains indistinct. In ecology, habitat, biome and ecosystem are all quite vague concepts, largely defined by the geographical features and ecological community in the area predominantly inhabited by a species (e.g., montane, acquatic, alpine). In evolution, the idea of a niche - taken as a set of 'dimensions' important to survival and reproduction - remains more abstract than is useful in the context of changing behaviour. At best, the niche has been conceptualized as a 'hyper-volume', or multi-dimensional space of resources such as nutrients, territory or mates used by organisms to satisfy fundamental biological needs. (Hutchinson, 1957) What we require is a way of gaining focus on levers and triggers of change that are extrinsic to people, or 'outside'.

One way of moving toward a more precise definition of 'external factors' is to divide environmental phenomena into three types - physical, biological, and social - as a function of how they influence behaviour. This division is supported by the sort of response that these different types of environment make to behaviour (a process that is part of the Evo-Eco approach - see Figure 3). First, the physical environment responds in simple Newtonian terms to behaviour: if you kick a stone, it flies away until its momentum dissipates. ${ }^{5}$ An animal, on the other hand, can be strategic in its response, such as when a rabbit avoids being caught by a predator by scampering in random fashion across the landscape. Finally, a component of the social environment, another human being, will respond in potentially very elaborate ways to a simple stimulus - for example forming a life-long plan to get revenge for a perceived wrong (e.g., the Count of Monte Cristo). Because these responses occur in different ways, human brains should perceive and respond to physical, biological and social factors in the environment differently when producing behaviour. Indeed, it appears that different kinds of deductions are commonly made with respect to physical, biological and social objects, as suggested by the literature on 'folk' physics, biology and sociology.

(Hirschfeld, 2001; Medin \& Atran, 1998; Povinelli, 2000; Ravenscroft, 2010) For example, physical and biological objects can be distinguished in three ways: physical objects are not expected to have internal motivation, while biological objects are (Inagaki \& Hatano, 2006); biological objects are embedded in unique hierarchies (i.e., the 'tree of life'), while artifacts can be in several hierarchies at once (Atran, 1998); and animals don't have specific purposes (e.g., tigers are not 'for' anything in particular), but artifacts do (e.g., hammers are for hitting things). (Greif, Nelson, Keil, \& Gutierrez, 2006) So these three types of environment are real in psychological terms, and hence should be distinguished in behavioural models. 
Two other types of argument also support this tripartite division: evolutionary and ecological. That is, the physical, biological and social environment also differ in genetic terms: the physical environment doesn't contain any genes, the biological environment (other animal and plant species) have a different gene pool from us, while the social environment is the current manifestation of our same-species gene pool. A final perspective is ecological, which makes reference to a species' niche. Conspecifics have the same niche (roughly speaking) as the focal individual, while members of other species will have at least somewhat different niche to live in. However, physical objects aren't restricted to a specific niche at all, but can exist anywhere on the planet's surface. 6

\section{Physical environment}

We can use evolutionary principles to draw further distinctions and to trace the development of these three different types of environment. Two aspects of the physical environment can be distinguished in technological terms relevant to behaviour. (Robert Aunger, 2010b) First, in most cases - as we saw with the top public health problems above - the behaviours public health workers are interested in changing typically involve manipulating a technological object to facilitate the behaviour's performance: condoms for safe sex, soap for proper handwashing, seat belts and air bags to avoid casualties in car accidents. Similarly, in marketing, the behaviour change problem is to increase use of particular products, which also tend to be objects, such as shampoo, telephones, or automobiles. Improvements in educational outcomes (another focus of behaviour change efforts) can depend significantly on students making better use of educational aids such as textbooks and computers. In all cases, these are relatively small-scale, rapidly improvable physical implements which are often significantly affected by use (and hence are prone to obsolescence). Objects are thus aspects of the physical environment which are manipulable, and tend to decay or get damaged as a consequence of use (e.g., chair, soap, hammer, laptop) (Robert Aunger, 2010b) 'Focal' objects are thus key to the performance of many of the behaviours people seek to change. Invertebrates have been shown to manipulate objects, (Kuba, Meisel, Byrne, Griebel, \& Mather, 2003; Mather \& Anderson, 1999) so this connection between behaviour and objects has had a long evolution. 7

A second aspect of the physical environment is also specifically adapted to producing behaviour. However, it evolved to a very modest degree in other primates, and significantly only in humans: what I will call 'infrastructure' is the consequence of long-term niche construction, conducted by human beings, often over generations. ${ }^{8}$ Infrastructure is the 'big stuff', often called the 'built environment' - things like a city's electricity grid, roads, skyscrapers, or the world wide web. It consists of modified aspects of the environment which are relatively inert or stable when used, remaining in roughly the same state, leading in part to their durability. (Robert Aunger, 2010b)

Thus infrastructure and objects respond differently in endogenous terms to behavioural interaction. Recognizing the dimensions of functionality in an object or infrastructure can help when thinking about how the technology itself can be modified to increase its ability to perform this function, or how its use can be modified by the person handling it to make use more easy or rewarding.

Specific motives have evolved for interacting with the physical environment. Associated with the production of infrastructure (or simpler forms of environmental modification) is the motive of Create (all the motives we identify as having specific evolved functions are capitalized to distinguish them from common usage), which causes people to improve their surroundings in durable ways that are likely to make greater resources available for consumption in the future (e.g., by producing machines which increase productivity over the power of muscles alone). Objects can be Hoarded, 
a motive designed to keep surpluses available for times when there might be a dearth of resources (the quintessential examples being water and food-stuffs). Also associated with objects is Play, a motive designed to motivate people to interact with objects, and develop the skills for their proper use. (Burghardt, 2005) Finally, Comfort ensures that people move away from uncomfortable conditions such as excessive heat or altitude. (R Aunger \& Curtis, accepted) (A full list of all the human motives to be mentioned here can be found in Table 1.)

Table 1: The Human Motives

\begin{tabular}{|c|c|c|c|c|}
\hline Label & Motive & Niche feature & Theoretical problem & Target \\
\hline Comfort & Maintain body & $\begin{array}{l}\text { Ecological } \\
\text { variation }\end{array}$ & $\begin{array}{c}\text { Pain } \\
\text { avoidance }\end{array}$ & Body \\
\hline Hunger & $\begin{array}{l}\text { Acquire metabolic } \\
\text { resources }\end{array}$ & $\begin{array}{l}\text { Ecological } \\
\text { resources }\end{array}$ & Optimal foraging & $\begin{array}{c}\text { Biological } \\
\text { environment, Prey } \\
\text { [Body] }\end{array}$ \\
\hline Fear & $\begin{array}{l}\text { Avoid hurt-from- } \\
\text { without threats } \\
\text { (predation) }\end{array}$ & Predators & $\begin{array}{l}\text { Predation/ accident } \\
\text { avoidance }\end{array}$ & $\begin{array}{l}\text { Biological } \\
\text { environment, } \\
\text { Predator }\end{array}$ \\
\hline Disgust & $\begin{array}{l}\text { Avoid hurt-from- } \\
\text { within threats } \\
\text { (parasitisation) }\end{array}$ & Parasites & Parasite avoidance & $\begin{array}{c}\text { Biological } \\
\text { environment, } \\
\text { Parasite }\end{array}$ \\
\hline Lust & Mate & $\begin{array}{l}\text { Sexual } \\
\text { reproduction }\end{array}$ & Mate selection & $\begin{array}{l}\text { Social environment } \\
\text { Relationships }\end{array}$ \\
\hline Attract & $\begin{array}{l}\text { Acquire high quality } \\
\text { sexual relationships }\end{array}$ & $\begin{array}{c}\text { Mate } \\
\text { competition }\end{array}$ & $\begin{array}{l}\text { Sexual } \\
\text { selection }\end{array}$ & $\begin{array}{c}\text { Social environment } \\
\text { Relationships }\end{array}$ \\
\hline $\begin{array}{l}\text { (Pair-bond) } \\
\text { Love }\end{array}$ & $\begin{array}{l}\text { Maintain high quality } \\
\text { sexual relationships }\end{array}$ & $\begin{array}{l}\text { Very dependent } \\
\text { offspring }\end{array}$ & Paternal investment & $\begin{array}{c}\text { Social environment } \\
\text { Relationships }\end{array}$ \\
\hline Nurture & $\begin{array}{l}\text { Rear offspring/ aid } \\
\text { dependent kin }\end{array}$ & Altricial live birth & $\begin{array}{l}\text { Kin selection/ } \\
\text { Inclusive fitness }\end{array}$ & $\begin{array}{c}\text { Social environment } \\
\text { Relationships }\end{array}$ \\
\hline Hoard & $\begin{array}{l}\text { Accumulate/ defend } \\
\text { surplus consumable } \\
\text { resources }\end{array}$ & $\begin{array}{l}\text { Social resource } \\
\text { competition }\end{array}$ & $\begin{array}{l}\text { Resource acquisition/ } \\
\text { defense }\end{array}$ & $\begin{array}{c}\text { Physical } \\
\text { environment, } \\
\text { Objects }\end{array}$ \\
\hline Create & Improve habitat & $\begin{array}{l}\text { Ecological } \\
\text { degradation }\end{array}$ & Niche construction & $\begin{array}{c}\text { Physical } \\
\text { environment, } \\
\text { Infrastructure/ } \\
\text { Objects }\end{array}$ \\
\hline Affiliate & Affiliate with groups & $\begin{array}{l}\text { Group-produced } \\
\text { resources }\end{array}$ & $\begin{array}{c}\text { Direct reciprocity } \\
\text { (reciprocal altruism) }\end{array}$ & $\begin{array}{c}\text { Social environment } \\
\text { Network }\end{array}$ \\
\hline Status & $\begin{array}{l}\text { Invest in status } \\
\text { improvement }\end{array}$ & Social hierarchies & $\begin{array}{l}\text { Indirect reciprocity } \\
\text { (reputation } \\
\text { management) }\end{array}$ & $\begin{array}{c}\text { Social environment } \\
\text { Network }\end{array}$ \\
\hline Justice & $\begin{array}{l}\text { Maintain functioning } \\
\text { of large non-kin } \\
\text { groups }\end{array}$ & Ultrasocial society & 'Strong' reciprocity & $\begin{array}{c}\text { Social environment } \\
\text { Network }\end{array}$ \\
\hline Play & $\begin{array}{c}\text { Acquire/ increase/ } \\
\text { hone skills }\end{array}$ & Learning & $\begin{array}{c}\text { Skill } \\
\text { acquisition }\end{array}$ & Brain, Reactive \\
\hline Curiosity & $\begin{array}{l}\text { Acquire knowledge } \\
\text { about the world }\end{array}$ & Memory & Uncertainty reduction & Brain, Executive \\
\hline
\end{tabular}




\section{Biological environment}

Our basic model of the biological environment is fairly simple, as any animal only adopts a few behavioural relationships with other species (see Table 2). In particular, there are three ecological relationships: an animal can be predator or prey to other large-scale animal and plant species, or serve as a host or vector to pathogens, which eat one from inside. Each of these relationships is associated with a specific psychological motive: Disgust helps us to avoid becoming a host (or vector) to parasites; Hunger is designed to maximize our intake when we are acting as predators on plant and animal species; and Fear (via the fight/flight/freeze mechanism) evolved for dealing with the proximity of predators (i.e., to help us avoid becoming prey). All of these relationships involve a biological agent passing through the body boundary in some form (e.g., by being eaten, taking a bite of the person, or infecting the individual as host). More generally, Curiosity leads people to explore their physical surroundings, to ensure they have up-to-date information on all available threats and opportunities, which are primarily about locations of food, potential predators and pathogen habitats.

More recently, however, humans have developed cultural relationships with other species. First, some species are used as products or to provide services (trees grown for wood, corn for fuel, sheep for wool, or a donkey used to pull cart). These are species we treat as if they were physical objects. Second, some species we see as 'pretty', and wish to have within view for aesthetic reasons, such as flowering plants and swards of grass, perhaps because they remind us of our ancestral condition in the African savannah. (Orians \& Heerwagen, 1992) These are species we treat as if they were part of the physical infrastructure. Third, other animals serve as pets: animals we keep in close contact without eating, because we are fond of them. These are species that are treated as if they were members of our own species. Thus, each kind of cultural relationship to other species constitutes a 'perversion' of a different kind of relationship to the environment, either physical or social.

Table 2: Types of Relations to Other Species*

\begin{tabular}{|c|c|c|c|}
\hline Name & Relationship & Motive & Examples \\
\hline \multicolumn{4}{|l|}{ Ecological } \\
\hline Predators & $\begin{array}{l}\text { Eats you from } \\
\text { outside }\end{array}$ & Fear & Bear, lion \\
\hline Parasites & Eats you from inside & Disgust & Bacteria, viruses, insects \\
\hline Prey & You eat it & Hunger & cow, cereals \\
\hline \multicolumn{4}{|l|}{ Cultural } \\
\hline Products & You use it & $\begin{array}{l}\text { [Treat like physical } \\
\text { object] }\end{array}$ & $\begin{array}{l}\text { Biofuels, transport } \\
\text { animals, trees as wind- } \\
\text { break }\end{array}$ \\
\hline 'Pretties' & You tend it & $\begin{array}{l}\text { [Treat like physical } \\
\text { infrastructure] }\end{array}$ & Flowering plants, grass \\
\hline Pets & $\begin{array}{l}\text { You keep it for } \\
\text { companionship }\end{array}$ & [Treat like social object] & Dogs, cats \\
\hline
\end{tabular}




\section{Social environment}

The human social environment has become more complex than the biological one. Most invertebrates don't have a social life, being born and then abandoned to their fate almost immediately. Mammals were the first large-bodied animal group to spend a significant proportion of their lifespans in the presence of conspecifics, with whom they had particular kinds of relationships. However, mammals didn't develop significant structure within their social groups, which remain largely egalitarian in nature. Primates were the first in our evolutionary lineage to develop hierarchical societies, in which there is privileged access to resources, including mates. (Boehm, 1999; Mitani, Call, Kappeler, Palombit, \& Silk, 2012)

Humans have developed social life to a unique degree. We live in very large groups that can be composed of multiple sub-groups. Some of these typically meet in particular locations, with associated infrastructure, such as businesses, governments, sports clubs, and religious organisations. Such organizations or institutions can be considered forms of social technology which facilitate new kinds of cooperative outcomes. Each of these can be thought of as a network of individuals linked through particular kinds of relationships, in which each individual is playing a particular kind of role, to help that organization achieve its designed ends. These networks can have regular kinds of structures (e.g., an organizational chart with a pyramidal shape) that dictate the ways in which it is possible to change roles within the organization (e.g., through appointment to a higher-status job by consensual agreement among others in the group).

More generally, social groups form networks, or structures within which one takes a place or position (e.g., social roles). Within these networks, there can be specific relationships, which are enduring dyadic interactions (e.g., mother-offspring). Playing a given role in an organization, network or relationship can involve activation of a particular motive. For example, Status maximization drives some people to become CEOs of businesses, while pleasure in skill development (the Play motive) leads others to become professional sportsmen. Play has also been extended in primates from object-play to social play, for learning the skills to interact with conspecifics effectively. (Burghardt, 2005) Affiliation is the motive to simply belong to a particular group, to share membership with others in a common goal. (R Aunger \& Curtis, accepted)

\section{Interactions}

The three basic components also interact. Such interactions occur prominently in the production of behaviour itself, but also in more complex ways to be described later.

\section{Behaviour}

The nature of behaviour is constantly changing (unlike the components we talked about previously). As a result, behaviour is represented as a process in the Evo-Eco Model in which bodies interact with their environments (represented as a blur between these two components in Figure 3). As mentioned earlier, control over this process has developed over time. In invertebrates, control is limited to the production of individual actions, or short sequences that have been linked together in regimented fashion by genetic evolution. We can mimic this through habit formation, which automatically produces learned sequences of actions. 
Efforts to achieve goals, on the other hand - regulated by the motivational system that evolved in mammals - enable us to chain together sequences that have not previously been performed, such as getting out of our seat, going to the refrigerator, fetching something from the shelf, moving to the oven, pushing various buttons, awaiting our food to be heated-up, putting the result on a plate, and heading to a table, where we sit down to eat. This entire sequence can be managed by our brains as a unit, ensuring that we find and digest food, thus stopping the reception of annoying internal signals that we are hungry.

Even more long-term plans can be formed by our executive brain to help us to achieve desirable end-states through a sequence of goal achievements, such as going to university for several years to get qualifications for pursuing a profession. Humans are unique in our ability to hold such longterm ambitions in our heads, and thereby attain end-states of high value that would otherwise not be reached, due to being pulled hither and thither by shorter-term goals.

Thus, behaviours need not be produced independently, one after the other. Rather increasing levels of control over behaviour production leads to multiple actions being produced together to achieve more hard-to-reach end-states. The result, from an observational point of view, is that these actions become statistically and functionally correlated - that is, 'chunked' together - in time and space. (Ostlund, Winterbauer, \& Balleine, 2009; Simon, 1974; Terrace, 2001) Behaviour has 'depth' or structure, in time, because a number of behaviours can be clumped together by our brains, and produced as a group, in sequence, thanks to motivational- and executive-level control.

Thus behaviour streams can be organised hierarchically into very long units ('get an education'), long units ('going to school'), short units called 'episodes' ('finding coat', 'saying goodbye to Mother', and 'getting bicycle') and very short, unconsciously executed units ('stepping down first step'). (M. Schoggen, Barker, \& Barker, 1963) These different scales of behavioural 'chunking' coincide almost exactly with the routine, scene, event and action hierarchies found in the literature on routine behaviour (Schank \& Abelson, 1977). Figure 4 presents an example showing several levels of integration over behavioural elements, with increasingly abstract chunks of behaviour culminating in a behavioural routine. Behaviour thus occurs in an on-going stream, as people move through their environment or produce streams of audible output. We have also adapted to parse our observation of these movements into events and higher-order chunks, (Schank \& Abelson, 1977; Zacks \& Tversky, 2001) or in the case of speech, to perceive the stream of sounds as words and sentences. (Pinker, 1994) ${ }^{9}$ As Figure 4 suggests, this 'chunking' of behaviour into higher-order units can occur recursively, so that a multi-level hierarchicalization can be performed, leading to quite complex behaviour patterns being controlled with relative efficiency in the form of daily routines.

The reinforcement learning model has been augmented to deal with hierarchically organized behaviour. This is because standard reinforcement learning models are subject to 'the curse of dimensionality'. According to the basic model, an animal can only learn to behave adaptively by engaging in trial-and-error learning. As a result, the time needed to arrive at a stable choice for action selection increases with both the number of different end-states in the environment and the number of available actions. In fact, the total number of actions needed to explore this space can increase exponentially. In a human context, with a complex environment and many behavioural options available, this would suggest that the standard reinforcement learning model quickly becomes computationally infeasible. (Richard S Sutton \& Barto, 1998)

One way to combat this scaling problem is to introduce hierarchical control architectures. (Barto \& Mahadevan, 2003; M. M. Botvinick, 2008) In hierarchical reinforcement learning, sequences of 
actions can be grouped into subroutines, each of which is evaluated according to its own subgoals. Thus, rather than select among a set of elemental actions, interpreted as relatively simple motor behaviors (such as grasping a spoon, scooping up some sugar, and depositing the sugar into a cup), hierarchical reinforcement learning allows the agent or animal to perform multi-action routines containing sequences of lower-level actions, casting them as a single higher-level action or skill (such as 'add sugar'). (M.M. Botvinick, Niv, \& Barto, 2009) These sequences, called options, have their own sub-goals. If a sub-goal is not met, it generates its own prediction error. These pseudo-reward prediction errors may not be associated with actual resources, but with achievement of an internally generated sub-goal that is but a stepping-stone toward the desired outcome. Nevertheless, the agent is motivated to reach these sub-goals, once the option gains control of behavior. Attaining the sub-goal yields a special reward signal, referred to as pseudoreward, which serves to sculpt the options policy. Placed within a hierarchical framework, pseudoreward prediction errors are used to learn which combinations of actions lead to a sub-goal, while reward prediction errors are used to learn which combinations of subroutines lead to rewarding outcomes. (R.S. Sutton, Precup, \& Singh, 1999) It appears this is how learning in the human brain occurs as well. (Badre \& Frank, 2012; Dayan \& Niv, 2008) In particular, prediction error responses at different levels of a hierarchical learning problem appear to recruit the same dopamine-based mechanisms - that is, dopaminergic responses seem to control learning from internal sub-goals as well as from end-goal achievement. (Ribas-Fernandes et al., 2011)

Reinforcement learning with temporal differences can thus be applied to domains with both sequential and hierarchical structure. Significant effort has therefore gone into the development of reinforcement learning algorithms which are specifically designed to operate in this kind of hierarchical context. (Barto \& Mahadevan, 2003; Dietterich, 2000; Parr \& Russell, 1998) Because they are associated only with the small number of actions in the subroutine, pseudo-reward prediction errors substantially reduce the complexity of learning. By introducing intermediate subgoals and arranging these into recursively more abstract structures, hierarchical reinforcement learning can explain the kinds of complex behaviors humans produce.

In fact, our discussion of the components of the Evo-Eco approach suggests the dimensionality problem of reinforcement learning is not really a problem once evolutionary and ecological reasoning is adopted. In particular, our investigation into the environment shows that it can be highly refined in practice, because a niche only has a reasonably small number of dimensions, reducing the number of factors to which an animal must actually pay attention. Only a few biological species fall into relationships with humans (e.g., millions of insect species go unnoticed by humans), while imitation is a common way of reducing the dimensionality problem in the social environment: simply copy what others are doing. (Richerson \& Boyd, 2005) We have shown that the physical environment is also concentrated into a few infrastructural complexes and focal objects to support specific behavioural performances. Further, behaviour itself is often controlled as hierarchical routines, which leads to a major reduction in the number of end-states that must be considered, while behavioural settings constrain the ways in which these different components can interact in particular circumstances, so that only a few kinds of actions are likely. Thus evolutionary and ecological constraints significantly limit the conceptual space that trial-and-error based reinforcement learning must explore to reach adaptive action selection outcomes. In 'real life', people make use of multiple 'kludges' that turn reinforcement learning into a tractable option for guiding behaviour. 


\section{Figure 4: A Hierarchical Behaviour Routine}

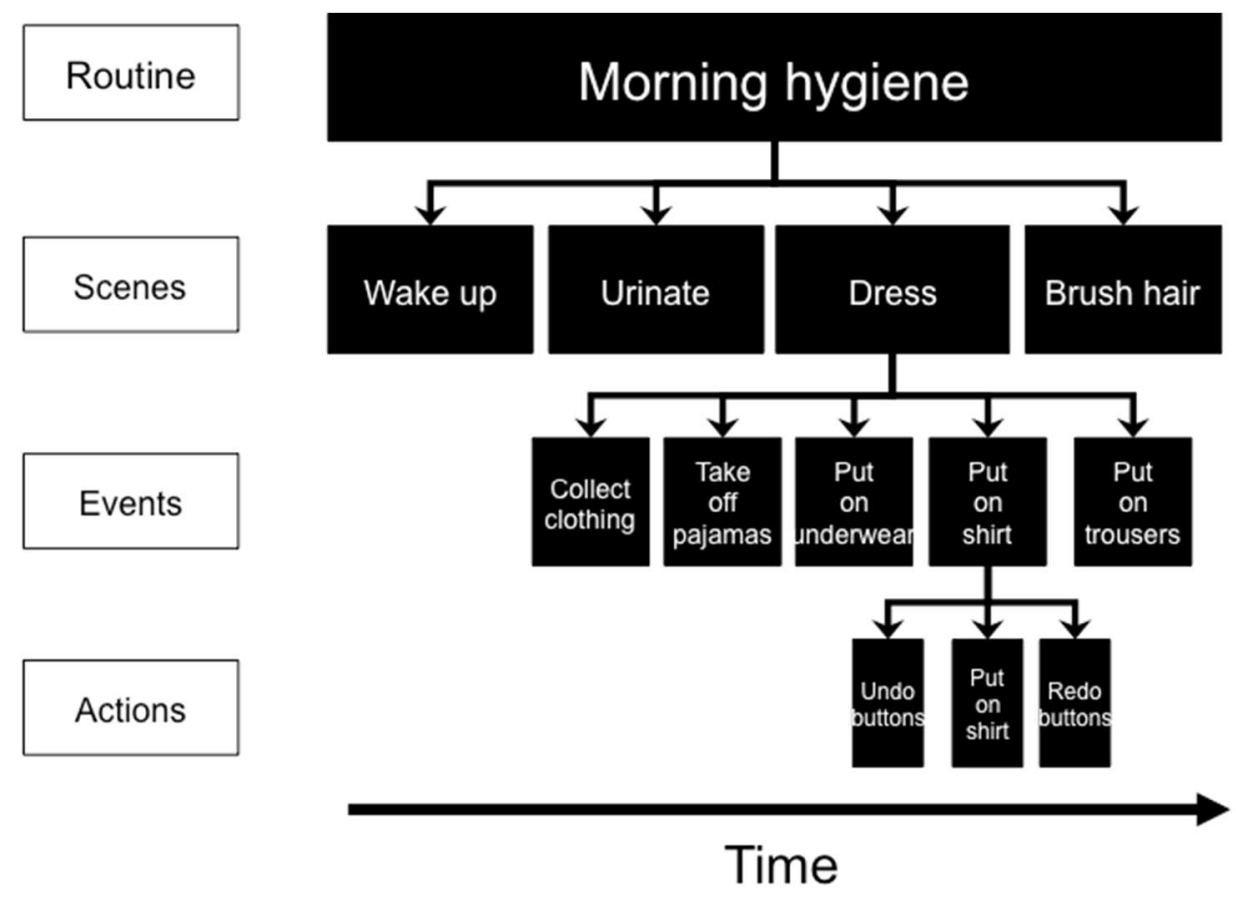

\section{Behaviour settings}

A more encompassing and involving process of interaction among components occurs when behaviour happens in specific 'settings' - a particular sequence of behaviours that fulfill a particular function. Examples include a church service, music class in school, pub quiz, basketball game, or political convention. Behaviour settings are networks of constraints on how animals behave in specific situations. The first manifestations of settings appear in the form of rituals and routines. ${ }^{10}$ The everyday activities of many animals are characterized by the stereotypical repetition of specific behaviours in particular sequences. It is well-known that major life events such as mating or territorial disputes proceed in a ritualized fashion - that is, using conventional signals and accentuated body movements - to secure the best outcome. (Krebs \& Dawkins, 1978; Maynard Smith \& Harper, 2003) These are situations of high risk and high reward in evolutionary terms; hence appropriate behavioural responses have been strongly selected, so that the best outcome can be most reliably secured. These adaptive responses are again likely to be the same, given a stable environment, so that they can become quite rigidly produced, perhaps by specific rules of response. Most animals, from ants to lizards to primates, also have daily routines in which they choose the same places and times to conduct a particular behaviour (e.g., feeding, getting water, marking territorial boundaries, resting, sheltering), day after day. (Lorenz, 1950; Serruya \& Eilam, 1996; Tinbergen, 1963) Since reinforcement learning results in optimal behavioural choices over time, then as long as conditions remain essentially the same, the same options should be chosen, and the same behaviours observed - hence the high degree of stereotypy in many animal behaviours. Behavioral rigidity - such as the preference to engage in specific acts at particular places and to take familiar routes between these places - is adaptive because it allows faster performance and requires less attention, enabling attention to be directed to other potentially varying aspects of the environment, such as the presence of predators. (Barlow, 1977; Boyer \& Lienard, 2006; Eilam, Zor, Szechtman, \& Hermesh, 2006; Young, 1988) 
Humans have elaborated such settings to a significant degree, thanks to the ability to play particular roles, often facilitated by modified physical infrastructures. A given behaviour setting often involves people interacting with focal objects (e.g., a Bible), specific kinds of infrastructure (e.g., a church building), and people playing complementary roles (e.g., choristers, parishioners, lay leaders). People can (often simultaneously) enter into an implicit contract to complete the execution of a particular setting, such as a church service, school class, shopping trip, sporting event, or private routine. Each participant plays a particular role within the setting, helping the group to achieve the setting's purpose, which may be to entertain (e.g., a Broadway show), educate (e.g., a biology class), acquire resources (e.g., a business strategy meeting), or avoid some danger (e.g., a fire drill). Playing a role typically involves performance of a particular sequence of behaviour to facilitate completion of the behaviour setting's function or task (e.g., the leader of a religious service leads the other participants through a sequence of events with symbolic significance). This can be considered one of the settings' routines.

Each role involving taking a particular position within the setting that is more or less central to the function of a setting. For example, a church service would be difficult to complete without a pastor to conduct it, and the organ-player is also quite important, but not as central as the pastor, while having a person to greet parishioners at the door is a functional luxury in many cases. It is often not necessary to refer to psychological states to predict the sequence of behaviour someone playing a particular role in a given setting will exhibit, so powerful are the regulatory pressures which dictate proceedings within settings. (Barker \& Schoggen, 1973)

Because these processes interact, through bodily development, brain-based learning and environmental modification, there can be consequences that are the result of this coevolution itself. That is, aspects of the environment can be adapted to the way brains and bodies work. Objects and infrastructure involved in settings often have design features that facilitate or invite the performance of certain kinds of behaviour - that is, they can be a component of a 'synomorphy'. (Barker, 1968; Gibson, 1979) ${ }^{11}$ This is a specific relationship between a person and an object, facilitated by the object's design, in which use of the object facilitates performance of a particular behaviour. For example, chairs help people to rest while remaining vertically oriented for work or social interaction. Synomorphies are adaptive kinds of 'fit' between environment, brain and body. For example, a bar of soap has a number of features that enable it to remove dirt from hands. It is about the size of a hand so it can be readily picked up and rubbed; it is relatively solid, so that it will last a long time, yet when wet, bits can be removed through easy friction to be left on the hand, at which point further friction will cause the bits of soap to foam, providing easier transport of dirt from the hand when washed off under a flow of water. All of these represent aspects of a synomorphy between the bar of soap and the human hand.

Settings involve dynamic, adaptive interactions between most of the components of the Evo-Eco Approach already described. As a result, settings are physically ephemeral in nature, like behaviour itself. Understanding how these components work together requires sophisticated investigations of the control mechanisms that manifest themselves through the dynamic interaction of brains, bodies and environments. For example, anyone who begins to engage in behaviours outside the remit of their role in a setting - such as causing disruption in a classroom - will be punished (e.g., by being told to leave the room) so that the other participants can achieve their goals. Such regulatory mechanisms can be discovered by observing them in action. (P. Schoggen, 1989) In social settings, this means that people performing their roles can help train others to perform theirs more appropriately - in effect, socially reinforced behaviour change. 
Roger Barker, originator of the behaviour setting concept, used cybernetic cycles to represent control mechanisms, operating not at the level of individual psychology, but at the level of the behaviour setting itself. (P. Schoggen, 1989) His 'eco-behavioral operating circuits' counter deviancies introduced by human or physical participants in the setting to maintain its progress through the setting's dynamic agenda. These are mechanisms for controlling the performance of settings, keeping people acting their routines in conformity with their adopted roles, using objects in ways consistent with their synomorphic nature, and correcting deviations from the normal pursuit of the setting's objective. He argued that these control mechanisms reside not just in psychological processes, but in the causal linkages between the physical, social and biological components of settings, making a setting a superordinate, dynamic, self-governing entity. (Barker, 1987) Thus, it can be argued that a setting is, essentially, a positive feedback system - like reinforcement learning - operating at a higher level of organization. ${ }^{12}$

Figure 5 is a representation of the Evo-Eco model with the additional sub-components that have been mentioned here.

\section{Figure 5: The 'Exploded' Evo-Eco Model (with sub-components)}

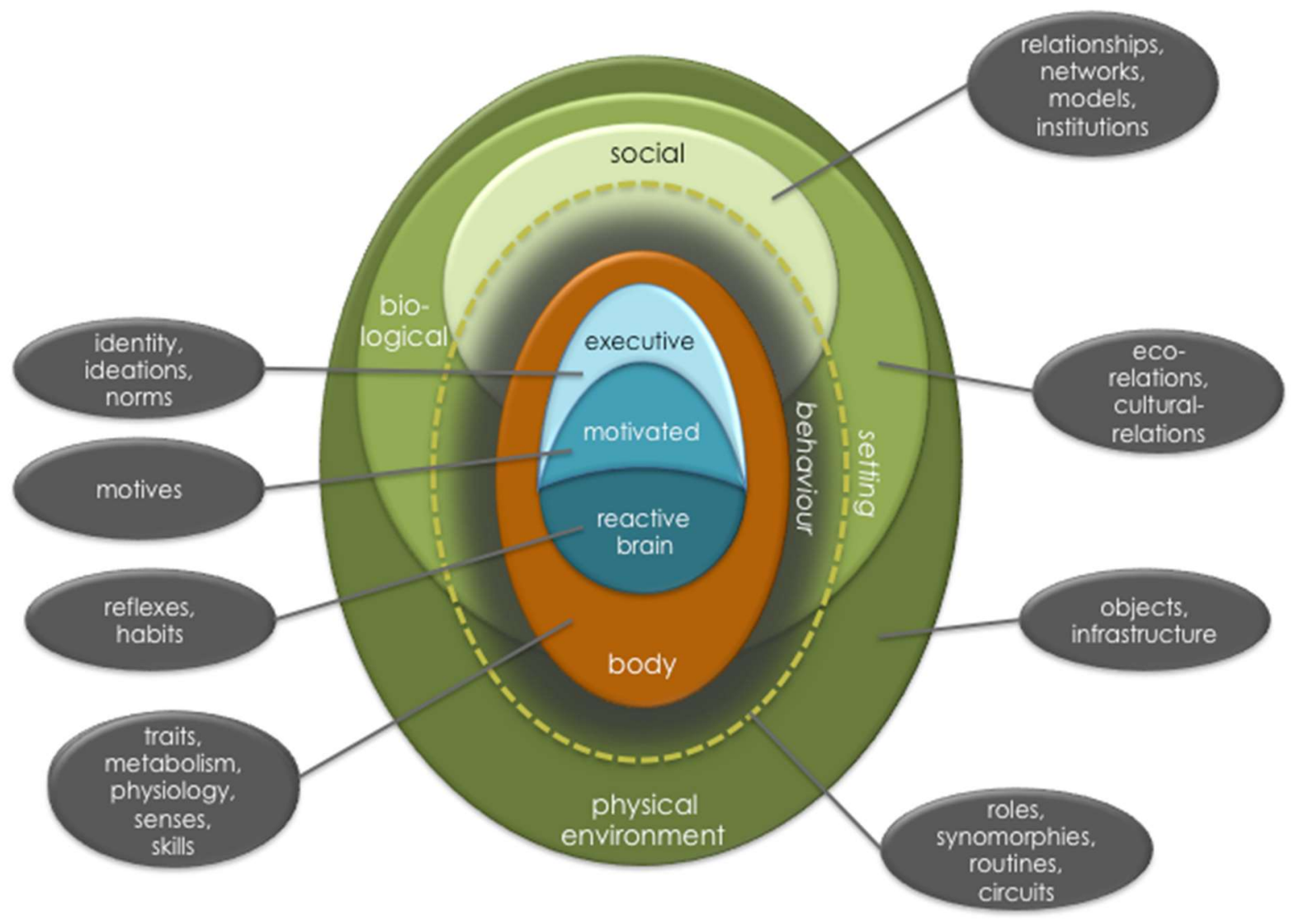




\section{How behaviour has evolved}

This completes our review of the science relevant to the components of the Evo-Eco approach. This procedure of component elaboration has elucidated what content can be found within brains, bodies, niche, behaviour itself and settings (as the coevolutionary adaptive product of the previous factors). ${ }^{13}$ This review has also presented details of mechanisms - such as levels of behavioural control in the brain, specific forms of learning and memory, or the operational rules of behaviour settings - knowledge of which can be used to manipulate behaviour in desired ways.

Figure 6 presents an enhanced Evo-Eco approach, which includes a table showing how the content of the Evo-Eco components has developed over evolutionary time. Particular developments in content or mechanisms can be linked to specific historical steps of evolutionary development (following along the rows of the table at the bottom of the figure). In the first step, with invertebrates, nervous systems were simple, and so were the mechanisms associated with the production of behaviour. Only the earliest forms of control, learning, memory and action selection were available at this point. ${ }^{14}$ Interactions with other species were limited to eating, being eaten, or being parasitized. Social life was nonexistent and behaviour settings consisted of ritualized competitive interactions and rigidly enacted daily routines.

\section{Figure 6: The Enhanced Evo-Eco Process Model}

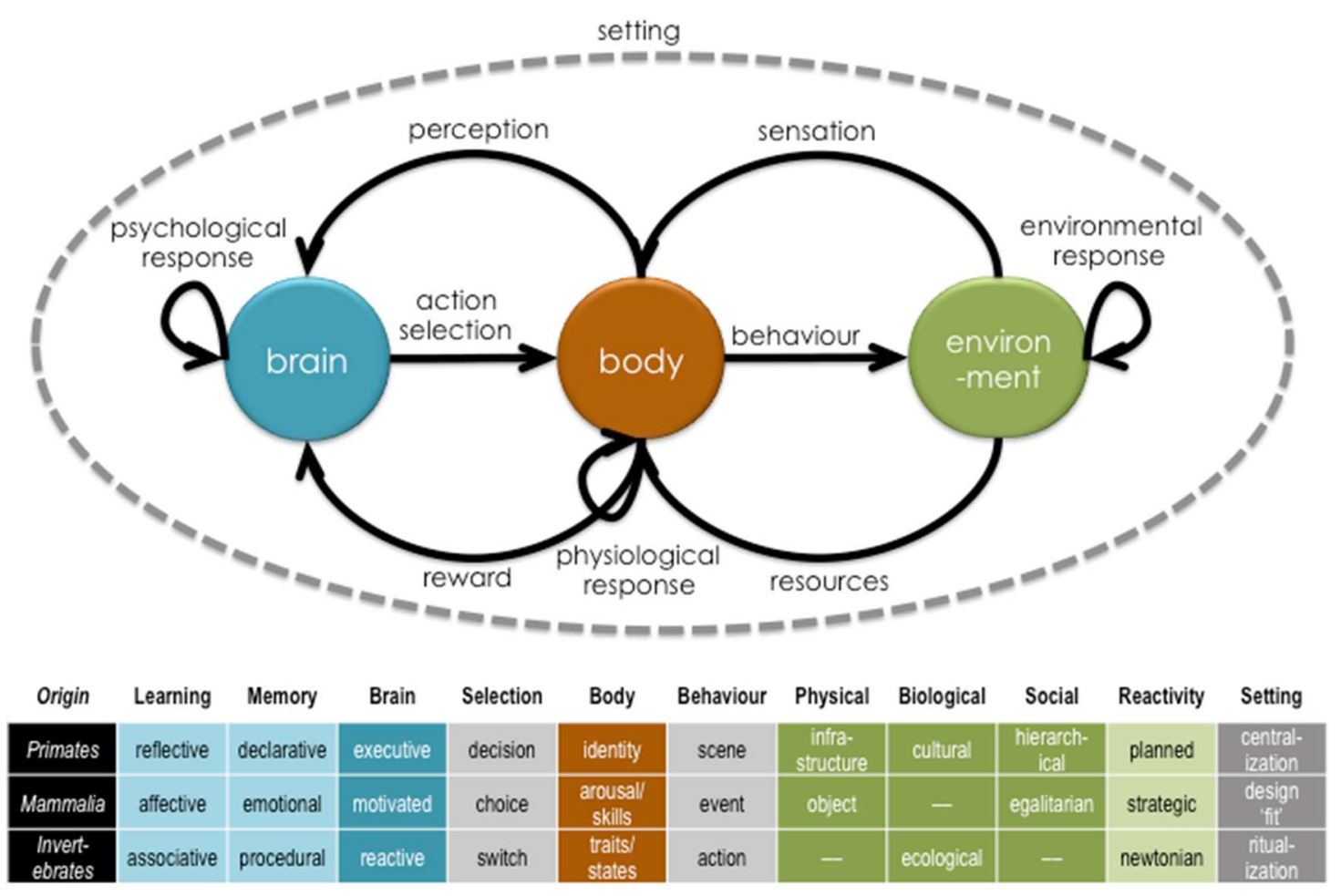

Considerably later, with the arrival of the mammals, more sophisticated mechanisms and versions of behavioural processes arose. With the development of psychological rewards (primarily through the dopaminergic midbrain system), animals could pursue goals, and came to pay specific attention to behaviours associated with goal achievement, being more likely to remember these associations in future as well through emotional memory. Behaviour production came to be 
chunked into related events culminating in particular end-states (called functional 'scenes') so that goals could be more reliably achieved. This was accomplished by utilizing more sophisticated action selection mechanisms that could evaluate alternative potential scenes through explicit choice over alternative courses of action more or likely to achieve goals. Meanwhile, some behaviours involved manipulations of the physical environment that resulted in long-lasting objects like cars and buildings; some interactions with these objects could be characterized as functional (i.e., were synomorphic). A particularly important mammalian adaptation was collecting into egalitarian social groups based around mother-offspring pairs. (Fox, 1984; Geary \& Flinn, 2001) These social groups enabled new forms of cooperative arrangements that produced new kinds of adaptive outcomes (e.g., collective defense).

Even more recently, either with the primates or our species itself, the most sophisticated contents and processes began to characterize the evolutionary ecology of behaviour. It is therefore often only within the last few million years that many of the features of human behaviour have become possible, such as executive level control, the production of entire routines, conscious decisionmaking and learning based on reflection on recent experience. All of the behaviour produced by such complex psychological processes often took place in a significantly rebuilt physical environment, and could involve the development of cultural relationships with other species, hierarchically organized societies, the 'modern' human family based on a long-lasting pair-bond motivated by Love, and behaviour settings in which people played many different social roles (with varying levels of centrality with respect to the functioning of the setting - an adaptation made possible by the increased specificity of social roles in a society with a significant division of labour).

All of these evolutionary developments through the phylogenetic history of our species can be seen as outcomes of the reinforcement learning algorithm in action over thousands of generations, producing a wide variety of adaptations in nervous systems and the environment, as well as interactions between these phenomena. Note that all of the early adaptations persist in our species, and should characterize human behavioural performances.

The fact that a coherent 'origin' story can be told for the contents of the Evo-Eco approach give it further credence. Given its presentation of much of the detailed content of the Evo-Eco approach, the table in the Enhanced Model can be used as a kind of check-list against which behaviour change specialists look for influences on the particular target behaviour they are interested in.

\section{Using the Evo-Eco Approach to explain public health problems}

To demonstrate the value of the Evo-Eco approach, we now want to show how it can illuminate the behaviour change task. In particular, we will now look to see exactly what kinds of learning failures can be associated with the need to change behaviour, and whether the Evo-Eco approach can account for them. We will take the field of public health as our field of inquiry here, because an obvious consequence of maladaptation is a failure to thrive, and public health is charged with understanding the causes of widespread morbidity and mortality. This field should therefore have good evidence of the kinds of maladaptations that can arise and cause the kinds of problems that people want to ameliorate through behaviour change.

Public health officials measure morbidity and mortality costs in terms of disability adjusted lifeyears (DALYs). If we look at the top twenty risk factors associated with lost DALYs on the global scale today, we see that each factor can be associated with both novel technologies and particular behaviours (see Table 3). It is not a surprise to find that specific behaviours underlie these problems - hence the recognition that behaviour change is important in the public health field. 
What is more surprising is the involvement of novel technologies such as Refined foods, cigarettes, condoms and cars, either as an aspect of the problem or as part of the solution for each major disease risk.

The involvement of technology becomes more reasonable when it is realized that technological innovation can occur many times within a genetic generation, while the brains of individuals that engage in the use of technological objects are produced by genes (interacting with the body and environment), which are modified only once a demographic generation (about 25 years in humans). Since the Pleistocene, the rate of technological innovation has increased over time, such that it took nearly a million years for primitive hand-axes to become more sophisticated, but now it requires only a few years for new versions of popular devices like computers or cars to be produced. Thus techno-generations have become shorter in many cases than demographic generations. As a result, technological evolution often proceeds more rapidly than genetic evolution, leading to a mismatch between what brains (as encoded by genes) suggest is an appropriate behavioural response to some environmental stimulus, and what would actually be appropriate in the techno-environments created by human groups. (Curtis \& Aunger, 2011) The result can be that environmental conditions have recently changed too rapidly for evolved psychological mechanisms such as reinforcement learning to cope effectively.

However, there are also purely structural problems with the ways in which learning can occur in the cases highlighted by public health which ensure that learning is often inappropriate. We can be more specific about the kinds of mismatch between technological and psychological processes that account for major public health problems by noting that there are three kinds of 'pathological process', or conditions under which normal learning does not take place, so that the problems persist without being rectified through experience (see Table 4). In each case, we need to distinguish between the kind of feedback (in terms of resources or rewards) that arise when individuals interact with the technology in the way the technology was designed for (e.g., using a condom to engage in protected sex) and the 'secondary' kinds of feedback which can happen incidentally, and not as a primary consequence of use of the technology (e.g., using a condom as a balloon).

The first kind of problem arises when a novel technology is highly motivating when properly used, but nevertheless doesn't provide evolutionary benefits. These tend to be bio-technologies that are intrinsically rewarding (or mimic the brain's own reward system), and which were designed to be stimulating, and hence get widely used to excess, such as synthetically produced alcohol and tobacco (risks \#4 and 5). Essentially, the problem is that humans have difficulty controlling their intake because the objects are super-stimulating. With super-stimulation, the effects of goal achievement through behavioural modification of the environment is mimicked without the normal pairing of some form of adaptive behaviour with goal achievement. Hence, the behaviour can be considered non-functional, as it doesn't produce any resources. Instead, a drug is simply ingested that provides the same effects as goal achievement directly to the brain (which reinforces an 'easy' route to reward and hence stimulates further drug-taking, and often physiological addiction as well). The problem is thus that a technology produces rewards that simulate the brain's dopamine-based reward system, thus getting used but without any evolutionary benefit (e.g., alcohol, cigarettes).

Second are novel technologies which are rewarding when properly used, but which also have harmful side effects (i.e., from secondary uses), such as driving. Automobiles are an excellent way of getting quickly from point $A$ to point $B$, but because the current infrastructure causes people going from point $B$ to point $A$ to drive right alongside those going in the opposite direction, there are sometimes deadly collisions, essentially as a side-effect of the speed with which cars enable 
people to move across the landscape. Thus, use of automobiles in over $99 \%$ of cases is rewarding, but in very rare cases can be significantly un-rewarding. However, this pattern of use teaches the evolved learning system that cars are such a 'good thing' that precautions (such as wearing seatbelts) do not seem necessary. An example from the list of Top 20 morbidity causes is domestic appliances that increase productivity but can reduce physical activity to such a degree that obesity results (risk \#10). So the side-effect learning pathology can involve incidental, or secondary changes in the environment as a consequence of the regular behaviour, but as such consequences do not always accompany the behaviour, they are not part of the normal learning process associated with that behaviour. Alternatively, the punishments (e.g., of obesity) are not as strong as the typical (functional) outcome (e.g., of reducing house work-loads), and so do not overwhelm the positive rewards, and therefore do not eliminate the practice.

Third, the proper use of some novel health-giving technology may not be intrinsically motivating, or at least not sufficiently rewarding to inspire use (given the costs of use, perhaps), or are rewarding in ways that don't lead to appropriate use (e.g., at the wrong time). For example, techno-evolution has thrown up some new technologies that help alleviate disease conditions, such as condoms to prevent the spread of sexually transmitted diseases like HIV (risk \#2). However, because they are perceived to reduce sexual pleasure, condoms tend to be ignored. Effectively, the problem is lack of uptake, which makes this technology a failed solution to a problem: people are still dying when they need not, given existing technology (if only people would use it). ${ }^{15}$ Lack of uptake exhibits the problem that the normal learning associated with performance of the target behaviour is negative. Hence the learning is to avoid the behaviour, as it is not psychologically rewarding. Learning is occurring appropriately in this case; it is just that the technological aid is not rewarding to use. ${ }^{16}$ In sum, super-stimulating technologies use the body (e.g., via signals that stimulate dopamine) to trick the brain; lack of uptake is (an object in) the environment not providing stimulation; and sideeffect mismatch is due to the brain itself being unable to calculate the appropriate reward function, given the structure of experience.

\section{Table 3: Top 20 Global Causes of Lost DALYs}

\begin{tabular}{|c|c|c|c|c|}
\hline $\begin{array}{l}\text { Risk factor for } \\
\text { burden of } \\
\text { disease }\end{array}$ & $\begin{array}{l}\text { Health } \\
\text { outcomes }\end{array}$ & $\begin{array}{l}\text { Contributory causes to } \\
\text { risk factors }\end{array}$ & $\begin{array}{l}\text { Novel } \\
\text { technologies }\end{array}$ & $\begin{array}{l}\text { Novel } \\
\text { behaviours }\end{array}$ \\
\hline 1/Underweight & $\begin{array}{l}\text { Malnutrition, } \\
\text { infection, low } \\
\text { birthweight }\end{array}$ & $\begin{array}{l}\text { Economic factors, } \\
\text { industrialisation and mass } \\
\text { production of food }\end{array}$ & $\begin{array}{l}\text { Convenience } \\
\text { foods* }\end{array}$ & $\begin{array}{l}\text { Loss of } \\
\text { traditional } \\
\text { feeding } \\
\text { practices (e.g., } \\
\text { bottle feeding, } \\
\text { weaning) }\end{array}$ \\
\hline 2/Unsafe sex & $\begin{array}{l}\text { STDs (HIV), } \\
\text { cervical cancer }\end{array}$ & $\begin{array}{l}\text { Rural-urban migration, } \\
\text { social breakdown, sex } \\
\text { industry, cultural factors }\end{array}$ & Condoms & $\begin{array}{l}\text { Increased } \\
\text { same/opposite } \\
\text { sex promiscuity }\end{array}$ \\
\hline $\begin{array}{l}\text { 3/High blood } \\
\text { pressure }\end{array}$ & $\begin{array}{l}\text { Cardiovascular } \\
\text { disease, stroke }\end{array}$ & $\begin{array}{l}\text { Industrialisation and mass } \\
\text { production of food, } \\
\text { sedentarisation of work } \\
\text { and leisure. }\end{array}$ & $\begin{array}{l}\text { Refined salt, } \\
\text { sugar, oils, etc } \\
\text { Labour-saving } \\
\text { and leisure } \\
\text { technologies }\end{array}$ & $\begin{array}{l}\text { Over- } \\
\text { consumption, } \\
\text { sedentary } \\
\text { lifestyle }\end{array}$ \\
\hline
\end{tabular}




\begin{tabular}{|c|c|c|c|c|}
\hline 4/Tobacco & $\begin{array}{l}\text { Cancer, heart } \\
\text { disease, } \\
\text { respiratory } \\
\text { disease }\end{array}$ & $\begin{array}{l}\text { Industrialisation and mass } \\
\text { production of cheap } \\
\text { psychoactive drug }\end{array}$ & $\begin{array}{l}\text { Tobacco high in } \\
\text { available nicotine } \\
\text { (cigarettes) }\end{array}$ & Smoking \\
\hline 5/Alcohol & $\begin{array}{l}\text { Cancer, heart } \\
\text { disease, } \\
\text { diabetes, } \\
\text { depression, } \\
\text { injuries }\end{array}$ & $\begin{array}{l}\text { Industrialisation and mass } \\
\text { production of cheap } \\
\text { psychoactive drug }\end{array}$ & $\begin{array}{l}\text { Refined alcoholic } \\
\text { drinks }\end{array}$ & $\begin{array}{l}\text { Regular and } \\
\text { binge drinking }\end{array}$ \\
\hline $\begin{array}{l}6 / \text { Water, } \\
\text { sanitation and } \\
\text { hygiene }\end{array}$ & $\begin{array}{l}\text { Diarrhoeal } \\
\text { disease, } \\
\text { respiratory } \\
\text { infection }\end{array}$ & $\begin{array}{l}\text { Insufficient public/private } \\
\text { investment in water supply } \\
\text { and sanitation }\end{array}$ & $\begin{array}{l}\text { Soap, toilet, water } \\
\text { treatment devices }\end{array}$ & $\begin{array}{l}\text { Handwashing, } \\
\text { toilet and water } \\
\text { filter use }\end{array}$ \\
\hline $\begin{array}{l}\text { 7/High } \\
\text { cholesterol }\end{array}$ & $\begin{array}{l}\text { Cardiovascular } \\
\text { disease, stroke }\end{array}$ & $\begin{array}{l}\text { Industrialisation and mass } \\
\text { production of processed } \\
\text { foods, sedentarisation of } \\
\text { work and leisure }\end{array}$ & $\begin{array}{l}\text { Low density } \\
\text { lipoproteins and } \\
\text { trans fats }\end{array}$ & $\begin{array}{l}\text { Use of } \\
\text { processed } \\
\text { foods, sedentary } \\
\text { lifestyle }\end{array}$ \\
\hline 8/Indoor smoke & $\begin{array}{l}\text { Respiratory } \\
\text { disease }\end{array}$ & $\begin{array}{l}\text { Cooking with solid fuels, } \\
\text { house design }\end{array}$ & Improved stoves & $\begin{array}{l}\text { Use of solid } \\
\text { fuels for cooking }\end{array}$ \\
\hline $\begin{array}{l}\text { 9/Iron, 11/Zinc, } \\
\text { 13/Vitamin A } \\
\text { deficiency }\end{array}$ & $\begin{array}{l}\text { Anaemia, } \\
\text { malnutrition, } \\
\text { infection }\end{array}$ & $\begin{array}{l}\text { Cereal-based diets, } \\
\text { recurrent infection, } \\
\text { helminth infection, early } \\
\text { weaning }\end{array}$ & $\begin{array}{l}\text { Micronutrient } \\
\text { supplements }\end{array}$ & $\begin{array}{l}\text { Consumption of } \\
\text { cereals/weaning } \\
\text { foods }\end{array}$ \\
\hline 10/Overweight & $\begin{array}{l}\text { Cardiovascular } \\
\text { disease, stroke, } \\
\text { diabetes, } \\
\text { cancer }\end{array}$ & $\begin{array}{l}\text { Industrialisation and mass } \\
\text { production of processed } \\
\text { foods, sedentarisation of } \\
\text { work and leisure }\end{array}$ & $\begin{array}{l}\text { Refined } \\
\text { salt/sugar/oils, } \\
\text { labour-saving and } \\
\text { leisure } \\
\text { technologies }\end{array}$ & $\begin{array}{l}\text { Over- } \\
\text { consumption, } \\
\text { sedentary } \\
\text { lifestyle }\end{array}$ \\
\hline $\begin{array}{l}\text { 12/Low fruit and } \\
\text { vegetable } \\
\text { intake }\end{array}$ & $\begin{array}{l}\text { Cardiovascular } \\
\text { disease, stroke, } \\
\text { cancer }\end{array}$ & $\begin{array}{l}\text { Industrialisation, mass } \\
\text { production of processed } \\
\text { foods }\end{array}$ & $\begin{array}{l}\text { Refined } \\
\text { salt/sugar/oils }\end{array}$ & $\begin{array}{l}\text { Consumption of } \\
\text { processed foods }\end{array}$ \\
\hline $\begin{array}{l}\text { 14/Physical } \\
\text { inactivity }\end{array}$ & $\begin{array}{l}\text { Cardiovascular } \\
\text { disease, stroke, } \\
\text { cancer }\end{array}$ & $\begin{array}{l}\text { Sedentarisation of work } \\
\text { and leisure }\end{array}$ & $\begin{array}{l}\text { Labour-saving } \\
\text { and leisure } \\
\text { technologies }\end{array}$ & $\begin{array}{l}\text { Sedentary } \\
\text { lifestyle }\end{array}$ \\
\hline 15/Occupational & Injury & Industrialisation & $\begin{array}{l}\text { Industrial } \\
\text { machinery }\end{array}$ & $\begin{array}{l}\text { Interaction with } \\
\text { machinery }\end{array}$ \\
\hline $\begin{array}{l}\text { 16/Lead } \\
\text { exposure }\end{array}$ & $\begin{array}{l}\text { Cardiovascular } \\
\text { disease, mental } \\
\text { retardation }\end{array}$ & $\begin{array}{l}\text { Industrialisation, mass } \\
\text { production of automated } \\
\text { transportation }\end{array}$ & Cars, lorries & Driving \\
\hline $\begin{array}{l}\text { 17/IIlicit drug } \\
\text { use }\end{array}$ & $\begin{array}{l}\text { HIV, overdose, } \\
\text { injury, infection }\end{array}$ & $\begin{array}{l}\text { Production and marketing } \\
\text { of cheap psychoactive } \\
\text { drugs }\end{array}$ & $\begin{array}{l}\text { Refined } \\
\text { psychoactive } \\
\text { compounds, } \\
\text { syringes }\end{array}$ & $\begin{array}{l}\text { Drug } \\
\text { consumption/inje } \\
\text { ction }\end{array}$ \\
\hline $\begin{array}{l}\text { 18/Unsafe } \\
\text { injections }\end{array}$ & Acute infection & Contaminated injections & Syringes & Syringe reuse \\
\hline $\begin{array}{l}\text { 19/Lack of } \\
\text { contraception }\end{array}$ & $\begin{array}{l}\text { Maternal } \\
\text { mortality }\end{array}$ & $\begin{array}{l}\text { Cultural factors, lack of } \\
\text { access }\end{array}$ & $\begin{array}{l}\text { Contraceptive } \\
\text { technologies }\end{array}$ & $\begin{array}{l}\text { Uptake of } \\
\text { contraception }\end{array}$ \\
\hline $\begin{array}{l}\text { 20/Childhood } \\
\text { sexual abuse }\end{array}$ & $\begin{array}{l}\text { Depression, } \\
\text { alcohol abuse }\end{array}$ & Cultural factors & & \\
\hline
\end{tabular}


* Items in italics constitute technologies and behaviours that are beneficial rather than detrimental to health

Adapted from (Ezzati et al., 2003); reprinted from Curtis (2012)

\section{Table 4: Types of pathological learning*}

\begin{tabular}{|lccl|}
\hline Case & $\begin{array}{l}\text { Design } \\
\text { Feedback }\end{array}$ & $\begin{array}{l}\text { Secondary } \\
\text { Feedlback }\end{array}$ & Top 20 Risk Factors \\
\hline Normal & $+/-$ & $+/-$ & [none] \\
\hline Super-stimulating & ++ & $+/-$ & $\begin{array}{l}\text { salt, fat and carbohydrate-dense foods, tobacco, } \\
\text { alcohol and psychoactive drugs }\end{array}$ \\
\hline Bad side-effect & +- & -- & $\begin{array}{l}\text { labour-saving means of production/transport; } \\
\text { syringe reuse; environmental toxins as by-product of } \\
\text { industrial production, lead poisoning }\end{array}$ \\
\hline Lack of uptake & - & $+/-$ & $\begin{array}{l}\text { convenience foods, micronutrient supplements, } \\
\text { sanitation, soap, contraception, condoms, cooking } \\
\text { stoves }\end{array}$ \\
\hline
\end{tabular}

* The plus and minus symbols imply positive and negative reinforcement from behaviour.

Problems thus arise when interactions between body and environment are less than optimal - that is, when rewards are produced without being accompanied by goal achievement (superstimulation), or secondary consequences (not part of the normal design loop) don't overwhelm normal rewards, or when regular punishments arise (or, at best, limited reward for behaviour production). In each of these scenarios, the basic reinforcement learning feedback process is disrupted in some way. Each of these problems 'tricks' the learning system in a way that precludes effective learning.

Thus, the fundamental question is how the Evo-Eco approach helps elucidate - and potentially ameliorate - the mismatch that appears to lie at the centre of most behaviour change problems. The suggestion is that the types of interventions required to change a behaviour should be a function of the kind of mismatch it represents. This is certainly true in the domain of public health (see Figure 7).

Behaviours stymied by 'lack of uptake' have the problem of increasing the use of a novel technological solution. For example, hygiene problems are often due to 'lack of uptake' mismatch (e.g., of soap for handwashing, toothpaste for toothbrushing, or surface cleaner for household surfaces), because such products are only minimally rewarding to use. One way increased uptake can be achieved is by adding (perceived) value to the unrewarding object - the typical job performed by marketing efforts for new products (e.g., making them 'sexy' or 'cool'). Alternatively, the technological solution can be itself improved so that it is more likely to be taken up (e.g., invention of a new hand cleansing technology).

'Side-effect' mismatch cases are solved by more appropriate (e.g., safer) kinds of use of some technology. Here, public health workers find it very difficult to curb behaviour at an individual level, 
so outside pressures must typically be brought to bear; hence the prevalence of legislative solutions for this kind of mismatch (e.g., seat belts and airbags are required components of car manufacturing processes; who can buy and sell guns or injection needles is severely regulated). Of course mandating provision of seat belts does not guarantee their use. There have been campaigns which have attempted to 'make real' the worst consequences of 'side-effect' mismatch, as in public health ads that show the death of loved ones as a result of not using seat belts.

The unique aspect of 'super-stimulating' mismatch behaviours is that they must be stopped or down-regulated, not started or up-regulated. Solutions in this case often resort to legislation as well, because such problems just can't be reliably motivated at an individual level. For example, smoking and alcohol consumption are highly regulated (who can buy, who can sell, where consumption is allowed), and price disincentives are brought to bear as well (e.g., high taxation on cigarettes and alcohol) - at least where the option of legislation is likely to be effective down to the individual level, thanks to good governance (e.g., in modern democracies). This category of mismatch has the additional aspect of dealing with the physiological dependencies that can arise from prolonged use. For smoking, this can be done through nicotine patches or similar methods to resolve nicotine dependency; alternatively, supportive social environments can be provided for those who wish to quit 'cold-turkey' (e.g., rehabilitation hostels).

Note that through this argument, we have shown that the Evo-Eco approach is able not only to identify the most important factors underlying problem behaviours, but to explain why certain behaviours become persistent public health problems in the first place: a small set of pathological learning processes are important causes of most of the most severe public health problems at a global scale. ${ }^{17}$ This investigation of the application of the Evo-Eco approach to public health thus suggests we are on the right track - although additional sorts of pathological learning may exist, and characterize other behaviour change fields, such as education or policy.

It is interesting to note that each major risk factor thus has the inappropriate use of some novel technology as an important cause, or the appropriate use of a novel technology as a way of eliminating or avoiding that disease. In effect, novel technologies are either the source of each major public health problem or part of its solution. (This doesn't mean that some change in technology is always going to be the intervention in a behaviour change campaign or program, just that technology frames the issue the campaign seeks to address in the first place.) What this analysis therefore suggests - at least for public health - is that behaviour change interventions should modify what these behavioural learning problems have in common: undesirable forms of learning from interaction with a novel technology.

The Evo-Eco Approach thus suggests that behaviour change efforts should be clear about how the target behaviour in a given project fails to be subject to adaptive learning (e.g., by classifying the learning disability that lies at the heart of the problem), and how the proposed intervention clears the learning blockage. Similar kinds of mismatch are likely to characterize other areas where behaviour change is required (e.g., policy, urban design, self-help), so we suggest that this is probably a general finding. 
Figure 7: Pathological Processes

Super-stimulation

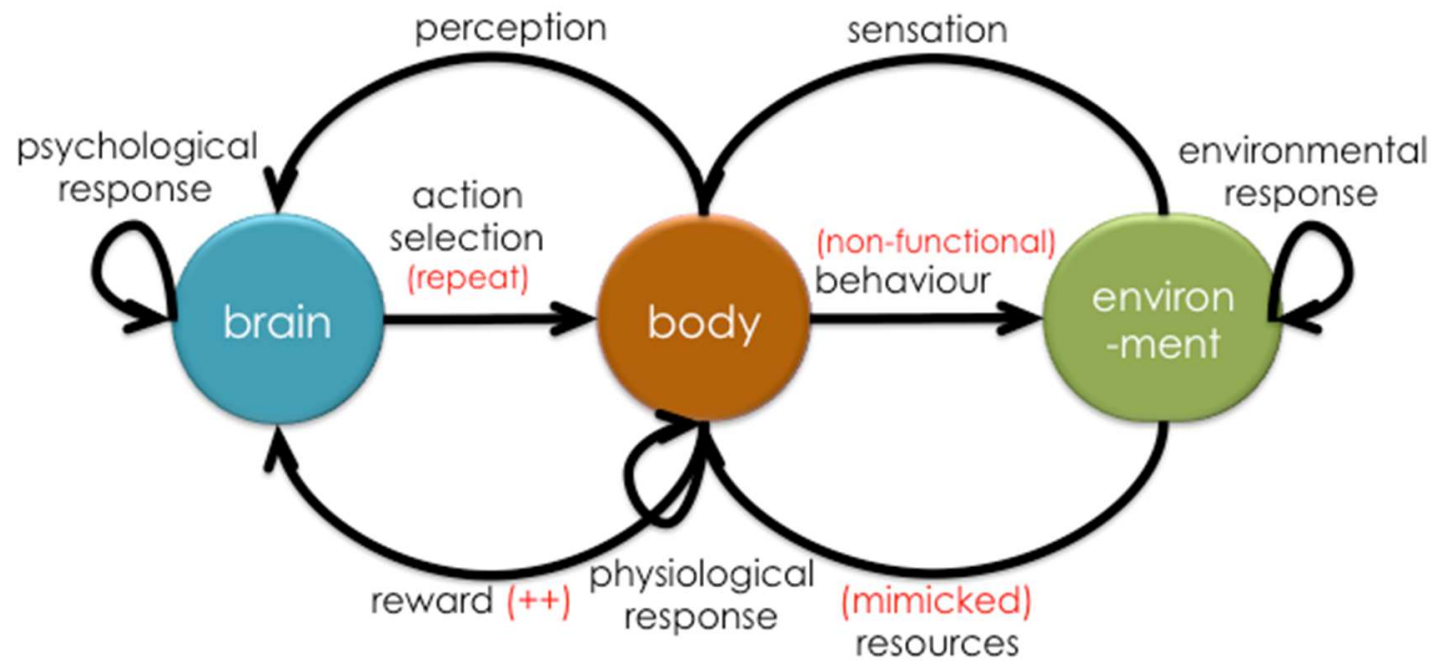

Lack of uptake

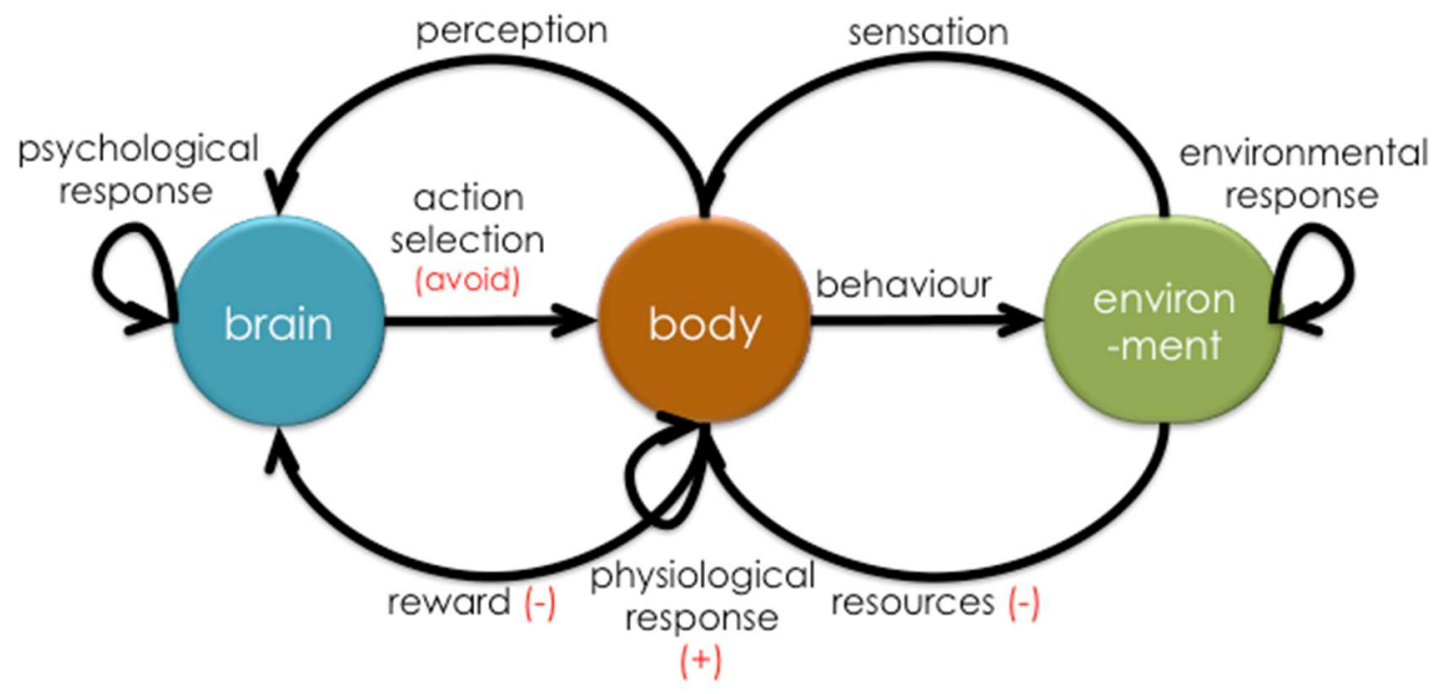




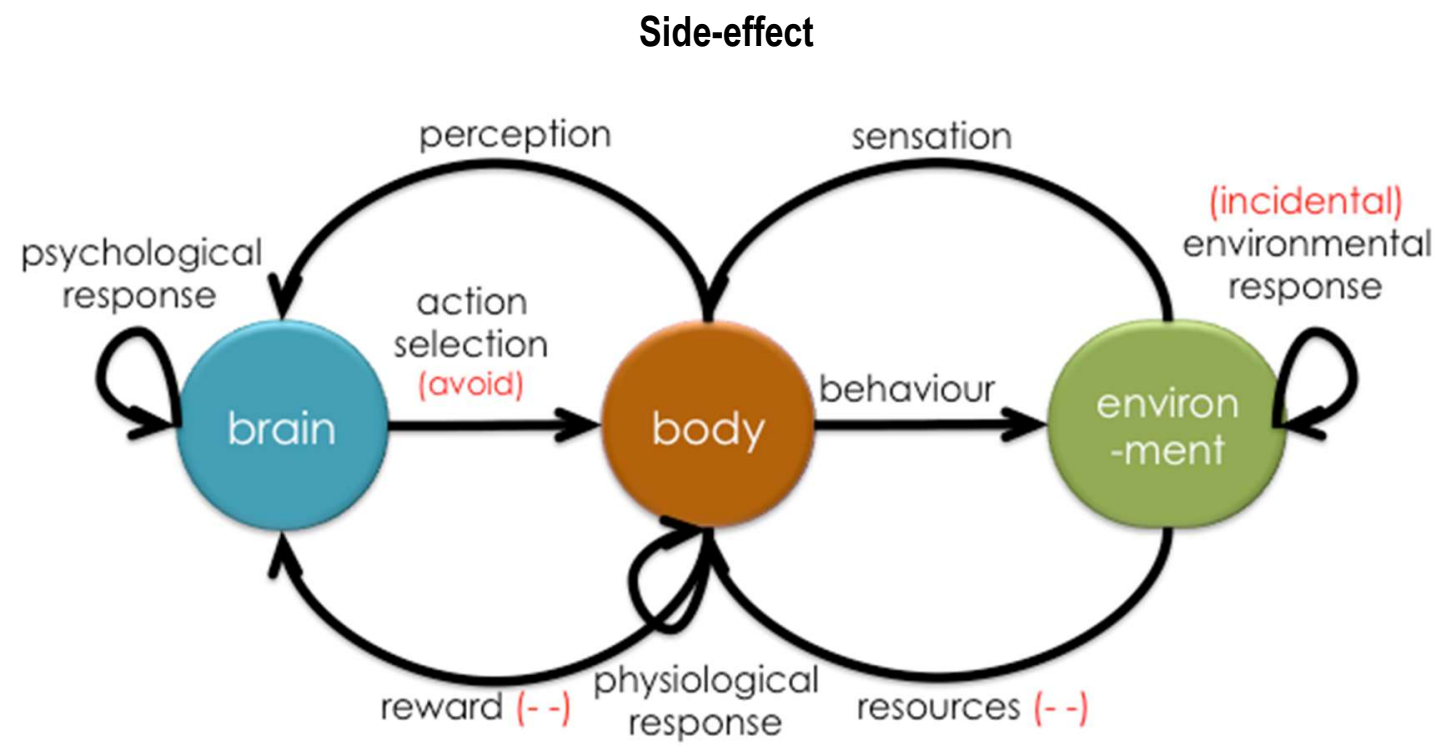

\section{Applications of the approach}

To justify these assertions, we now want to show how the Evo-Eco approach can be applied to various kinds of behaviour change contexts. This application should show that the approach can identify those factors which have proven to cause problems in modifying behaviour in each case.

\section{An example from self-help: smoking cessation}

One such context is self-help programs. For example, helping people to stop smoking can be pursued at many levels (e.g., via a policy to forbid cigarette advertising or smoking in public places - considered in the Evo-Eco approach as part of the general niche). Here we concentrate on personal means of quitting, using advice taken from the American Cancer Society's 'Guide to Quitting Smoking'

(http://www.cancer.org/Healthy/StayAwayfromTobacco/GuidetoQuittingSmoking/index).

This is seen a process (as it should be, if behaviour change requires learning), broken into four phases. The first phase involves making the decision to quit smoking. This must include a strong, personal commitment to quit by the target individual (executive control). Such a decision may follow a 'tipping point' event (i.e., point at which there is a deep recognition of the need to quit, perhaps because someone close developed health problems related to their smoking). This can involve adopting a new role (i.e., a 'non-smoker' identity - stored in the declarative memory associated with executive control). Practicing saying, 'No thank you, I don't smoke,' can reinforce this new identity.

The second phase is planning a quit date (within a month of the decision, to provide enough time to prepare). Preparations should include tasks such as:

- Picking the date and mark it on the calendar (physical reminder)

- Getting rid of all the cigarettes in the house, car, and at work (removing target objects from behaviour settings) 
- Stocking up on oral substitutes - sugarless gum, carrot sticks, hard candy (replacement objects)

- Telling friends and family about the Quit Day and setting up a social support system (social environment) such as a group program or a friend or family member who has successfully quit.

The third phase is Quit Day itself. On this day, individuals should not smoke, keep active by walking, exercising, or doing other activities or hobbies (behaviour replacements), drink lots of water and juices while avoiding alcohol (biological environment), begin using nicotine replacement (object), and attend stop-smoking class (social environment).

The fourth phase entails dealing with withdrawal, both physical (due to chemical addiction) and mental. Nicotine replacement and other medicines (biological environment) can help reduce the symptoms of chemical dependency. Sustaining the mental part of quitting can involve: avoiding temptation (e.g., staying away from people and places associated with smoking), and disrupting behaviour settings so that habits can change. Smoking typically becomes linked with specific situations - such as socializing with friends, at parties/clubs/bars, when taking a break at work or school, or while driving the car. (Best \& Hakstian, 1978) It can take time to 'un-link' smoking from these settings (e.g., by taking a different route to work, or taking a brisk walk instead of a coffee break). In particular, breaking physical habits can be helped by choosing novel things to keep the mouth and hands (body) busy, such as sugarless gum or hard candy (objects), as well as needlework or woodworking (behaviour replacements), to provide distraction from the urge to smoke. Rewards can also be used (motivation enhancement): quitting smoking is not easy, so rewarding good practice is reinforcing: put the money saved on tobacco in a jar every day and then buy a weekly treat (emotional memory, associated with motivation).

Finally, the 'staying quit' phase, during which the individual must plan for how to cope with recurrent temptations and the situations in which smoking used to occur. Tricks here include remembering that:

- Breath smells better, stained teeth get whiter, yellow fingers and fingernails disappear, sense of smell returns to normal (body)

- Food tastes better; everyday activities (such as climbing stairs or housework) no longer leave the individual out of breath (comfort motive)

- Smoking is expensive (physical environment)

- Smoking is less socially acceptable now (norms)

- Smoking not only harms your health but it hurts the health of those around you (manners)

- People with children probably want to set a good example for them (nurture motive)

This advice, given for developing an effective self-help program to quit smoking, can be easily accounted for by the Evo-Eco approach. In fact, the approach justifies the advice more naturally than most currently popular models, as they are not intrinsically dynamic, sensitive to place and particular motives, nor to the use of specific objects, and effects on the individual's body. Thus, we believe the Evo-Eco approach to be not only easily generalized to self-help problems, but also to more readily account for what is found to be significant in practice than its primary competitors: health psychological, social marketing and behavioural economic models. ${ }^{18}$ 


\section{An example from sport science: The 100 meter sprint}

To show the true generality of the Evo-Eco approach, we can see how it even applies to a 'nontraditional' behaviour change context: improving athletic performance - the job of sports scientists. In this field, the classic example is the 100 meter sprint, because it constitutes the pure behaviour of getting from point $A$ to point $B$ as quickly as humanly possible. The Evo-Eco approach can parsimoniously explain what sport psychologists and physiologists have found to be important. (This section is based in large part on factors mentioned by the International Association of Athletics Federations' '100 meters - For the expert' http://www.iaaf.org/community/athletics/trackfield/newsid=4666.html, and http://en.wikipedia.org/wiki/100_metres.) Recognizing the race as a behaviour setting immediately focuses attention on the different classes of roles: the runners, the person who fires the starting pistol, the person who judges the winner, and the audience. There are also important rules associated with this setting which define how the various players perform their roles (e.g., the false start rule). Further, the race takes place in a stadium with a running track of specific dimensions (infrastructure).

The race is also recognized by sports experts as a dynamic sequence of events, which they describe in terms of five phases. Different elements of the model become important in each phase of the setting (i.e., as expected, the rules controlling execution of the setting are specific to each step in the functional sequence). Prior to the race, the runners can engage in role playing: stretching (body), goofing to the camera as a way to relax, and thus not 'freeze up' during the race (relaxing into reactive control); while others engage in psychological warfare with other competitors (their social environment) by 'bigging themselves up' (e.g., wearing gold-coloured shoes to emphasize their confidence of coming in first place, or getting into the blocks last). Athletes have also been taught to engage in repeated imaginary rehearsal of each step of the race (sometimes called 'visualization'), a process enabled by executive control. They will have eaten a specific regimen of food at a specified period before the beginning of the race (biological environment) as well.

In the reaction phase, the runners settle into their starting blocks (object), curl up into the crouching position (body), found to be best for an explosive start, and await the gun (object). When the gun fires, they have incessantly trained to respond automatically, in a fear-based (motive) startle response (reactive-level control), which minimizes the time between the beginning of the race-time and their progression down the track (because conscious information processing takes longer).

Then the 'acceleration' or 'drive' phase begins, over the first 30-50 meters of the race. This is primarily about accelerating by using a particular 'forward lean' as they run while gradually becoming upright (body) in order to minimize the time spent at less than maximum velocity, but performance is also constrained by the track surface (infrastructure), interacting with the runners' shoes (object).

Phase three is the 'maximum speed' phase, characterized by stride length (body: Usain Bolt is 6' 5 " tall, and only needs 40 paces to cover 100 meters, where others require 45), stride pace and ground contact time, whether the track is wet or there is a head-wind (physical environment), and the level of the athlete's 'desire to win' (status motive). This is followed by the 'deceleration' stage (over the last 20 meters), as there is an accumulation of lactate in the leg muscles and fatigue of the central nervous system (body; Carl Lewis slowed down more gradually than any other runner, allowing him to emerge in the last section of the race). Finally, there is the finish, as athletes bend 
their torsos (body) toward the finish line (infrastructure), in competition with others also bending over (social environment) to snatch victory from their opponents (one competitor flung himself across the finish line in order to secure a medal at the 1988? Olympics).

Note that, again, the Evo-Eco approach has no difficulty in accounting for the kinds of factors that experts in this area have found to be effective in improving athletic performance, whereas very few of these factors would be covered by the currently popular models of behaviour change in health psychology or behavioural economics. Indeed, it is instructive that the factors mentioned by empiricists can be found in each category of the Evo-Eco Approach (e.g., at least one factor can be found in the causal categories of brain, body, physical, biological and social environments, setting and niche) - suggesting they are all necessary components of a general framework for studying behaviour change.

\section{Comparison to alternative behaviour change approaches}

The Evo-Eco approach represents a powerful way of thinking about behaviour, and should have an impact on how projects to change behaviour are formulated. This is because several aspects of the Evo-Eco approach are radically different from current approaches to behaviour change. First, its theoretical foundation lies in evolutionary biology, a more fundamental science than the cognitive psychology on which other behaviour change approaches are based. ${ }^{19}$ Most behaviour change programs derive their theoretical inspiration from the fields of health psychology and behavioural economics, where the most extensive efforts at theorizing behaviour change have been made. These fields have in turn based their theory on cognitive psychological principles. In particular, the currently dominant models of behaviour change - such as the Theory of Planned Behaviour, (M. Fishbein \& Ajzen, 2010) and Health Action Process Approach (Schwarzer, 2008) in health psychology, and rational choice theory, (von Neumann \& Morgenstern, 1944) used as the foundation for modeling behaviour in economics and political science - argue that behaviour maximizes expected utility. That is, behaviour is driven by the choice of that future outcome which is most highly valued, discounted by beliefs about how likely it is that such an outcome can be achieved. 20

Expected utility maximization tends to be measured by asking people about consciously experienced mental constructs. Constructs are hypothetical mental states or representations, the content of which can be reported by individuals (e.g., in response to questionnaires). Thus, most health psychology research models a state of health as a function of perceived risk of disease, and perceived behavioural control over achieving such an end. A behavioural economist, on the other hand, might be interested in the perceived value of a pension of a specific size upon retirement as a function of the economic goods that must be foregone now to save such an amount. ${ }^{21}$ Similarly, self-help programs typically rely on will-power, a high-level form of behavioural control which is known to be limited in important ways, (Roy F. Baumeister \& Tierney, 2012) while policy-makers have normally assumed that people respond rationally to the constraints their policies place on people's activity. (Coleman, 1990; Riker \& Ordeshook, 1973) But campaigns that emphasize enhancing knowledge or altering attitudes frequently have little effect upon behavior; there is often a weak relationship between attitudes and/or knowledge, and behavior. (Armitage \& Conner, 2001; McKenzie-Mohr \& Smith, 2000). This is because the assumption of rational or cognitive causation is often false: behaviour - or at least the behaviours of interest to behaviour change specialists - is often largely caused by automatic (e.g., habitual) processes (R. Aunger, 2007; Mittal, 1988; Neal, Wood, Labrecque, \& Lally, 2012) and environmental factors, (Stokols, 1995) both of which are ignored by expected utility models. For example, many illnesses are significantly influenced by the degree of economic inequality in a 
society, (Wilkinson, 2005) and physical activity depends upon civic resources for exercise. (Owen, Humpel, Leslie, Bauman, \& Sallis, 2004; Sallis et al., 2006) To the extent that behaviour change campaigns are founded on such theory - either explicitly, or implicitly (because long exposure to these approaches has coloured the discourse about behaviour change to such an extent that no one talks of anything but psychological constructs) - this theoretical bias toward exclusive reliance on high-level cognitive factors can account for the rather dismal record of under-achievement in terms of causing widespread change.

Second, the Evo-Eco approach is framed at a categorical rather than variable level. Health psychological models are traditionally concerned with relationships between individual variables such as intention or self-efficacy, while the Evo-Eco approach is couched in terms of causal categories like body and social environment (although structural relations between variables within these categories can be specified). This makes Evo-Eco a very general approach, whereas many health psychological approaches and behavioural economic 'heuristics' or 'biases' are designed to explain a specific class of behaviour. As we have shown, the Evo-Eco approach can be readily applied to public health, marketing, self-help and even sport psychological problems.

Third, it does not distinguish between distal and proximate causes of behaviour, with all proximate causes being psychological, as is true of the expectancy-value approaches. Whenever behaviour change models are augmented with demographic or environmental factors (M Fishbein, Triandis, \& Kanfer, 2001; B. R. Flay et al., 2009), these tend to be included as distal variables that have no direct impact on behaviour, but rather filter through cognition, and so (in most cases) are not measured. 22

In contrast, the Evo-Eco approach sees behaviour as radically embodied and situated. (Barker, 1968; Barrett, 2011; Clark, 1997; Gibson, 1979; Hutchins, 1995) That is, factors other than cognition are considered active and present in the moment of behaviour, having independent causal influence on activity. For example, the environment is theorized to have its own structure, and hence plays a formative role in behaviour production, rather than being seen as an amorphous set of 'barriers' (its typical role in behaviour change models). In particular, synomorphies exist between people and objects, infrastructures provide larger-scale support for the performance of certain behaviours, and behaviour settings structure the dynamic interaction among these elements over time.

Thus, behaviour is seen as a dynamic interaction with other model elements, rather than as the consequence of previous steps in a linear causal model (the 'box-and-arrows' diagram other approaches use). This forces behaviour change workers to recognize the intrinsic dynamism of behaviour, and its ephemeral nature, with the target behaviour occurring within a stream of priorand post-activity. Indeed, the stream of behaviour is recognized to have its own temporal structure, being chunked into hierarchically-controlled sequences in which there tends to be dependence of later events on the successful accomplishment of earlier ones (e.g., you can't do $Z$ without having done $X$ and $Y$ first). In this way, behaviour is seen as being intrinsically physical: it is instantiated as events in time and space, enacted by bodies, with the participation of organic brains, not calculating engines.

The benefits of taking this new approach have been several. First, there are no competing approaches that identify the set of problems that worry behaviour change workers theoretically (e.g., it delineates the domain of public health concerns and provides a categorization of its problems). Here, this has been achieved through the argument that they arise through a mismatch between evolved psychological proclivities and modern, technologically modified environments. 
Second, strong, explicit links can also be made from this theoretical foundation, to a behavioural model, and to the practice of intervention project design, so that formative research reflects theoretical concerns, and interventions can be different because of what theory says is potentially important, making significant behaviour change more likely to occur.

Third, with its view of the brain as an evolved organ, not a failed computer (as in behavioural economics), the Evo-Eco approach also provides a more positive view of human capabilities: rather than trying to make use of 'biases', it emphasizes the behaviour change 'problem' as one of channeling natural, internally-generated action impulses. People are naturally active - in order to stay alive in constantly changing environments, we must explore our surroundings to keep up-todate on what threats and opportunities have arisen. (R Aunger \& Curtis, submitted; Freeman, 1999) Seeing behaviour change as helping people to harness this 'energy' more profitably can remove any stigma that the field might inspire among those who see it as controlling and tyrannical.

Compared to health psychology and behavioural economics, then, our approach places greater emphasis on:

- the physicality of behaviour (physical environment, bodies)

- $\quad$ place (e.g., space with designed infrastructure)

- time (e.g., weekends)

- brain-based mental processes (e.g., mental representation, goal achievement, memory)

- psychological dynamics (i.e., learning)

- non-cognitive processes (e.g., motivation, habit)

- bodily states (e.g., hunger, sexual arousal)

- behavioural dynamics (i.e., setting-based routines)

- behavioural interdependence (e.g., chunking, sequence dependence)

\section{Conclusion}

In this paper, we have developed a new theoretical approach to behaviour change, based in evolutionary biology and ecological psychology, called the Evo-Eco approach. A significant benefit of adopting an evolutionary approach to behaviour is that it also provides the basis for a theory of behaviour change: if behaviour is an adaptation, then the need for change should only arise when there is maladaptation. For a maladaptation to become a public concern (in education, health or policy arenas), it must typically be characteristic of a significant number of people for a long period of time (i.e., not just a transient, idiosyncratic 'error' in a small group) - that is, a case of widespread, persistent 'bad' behaviour. This situation is most likely to arise when behavioural learning systematically fails to reach optimal outcomes, because this attacks the core mechanism of adaptive response; in effect, the interaction between behaviour and environment is likely to be 'broken' in such cases, and learning fails when the behaviour-feedback relationship is not normative.

The Evo-Eco Approach is novel, as it has intellectual foundations in evolutionary biology, with content from neuroscience and ecological psychology - sources unlike the cognitive psychology that constitutes the foundation of behaviour change approaches in health psychology and behavioural economics. This science is more fundamental than cognitive psychology, and hence more likely to be insightful. 
The Evo-Eco model is more general than alternatives, including explicit treatment of the environment and body, not just the brain, and thus provides a much richer source of potential insights. It emphasizes behaviour as a complex, dynamic interaction between bodies and environments. Hence behaviour needs looking at for proper understanding (i.e., questioning in a context outside performance of the target behaviour is unlikely to be very informative). (Barker, 1968; Roy F Baumeister, Vohs, \& Funder, 2007) It also suggests that behaviour change efforts should be clear about how the target behaviour is not subject to adaptive learning (e.g., by classifying the learning disability that lies at the heart of the problem), and how the proposed intervention clears the learning blockage. For example, hygiene problems are due to 'lack of uptake' mismatch (e.g., of soap for handwashing, toothpaste for toothbrushing, or surface cleaner for household surfaces), because such products are only minimally rewarding to use (mostly just sensory benefits). This implies that any intervention or marketing effort should 'add value' to such products through some learning mechanism (e.g., making them 'sexy' or 'cool' or by adding functionality to the product itself).

Of course, the ultimate proof of utility is evidence that the approach changes relevant behaviours. In this regard, the Evo-Eco approach has been used to develop a scalable program to promote handwashing with soap after key events (primarily contact with faeces) in rural Indian villages; a randomly clustered trial showed that the practice went from being virtually absent to being practiced by roughly one-third of the population after a two-day visit by four health promoters to each village, six months post-intervention. (Biran et al., submitted) Based on this success, EvoEco is currently being used to develop interventions in other projects, such as child complementary feeding practices in Indonesia and multiple behaviours related to diarrhea prevention in Zambia.

Another proof of the utility of any theory derives from its ability to help people generate novel predictions. One such prediction from the Evo-Eco approach derives from its emphasis on roleplaying within behaviour settings, where it was assumed that the ability to learn to repeatedly perform a novel behaviour within a setting is affected by its placement in the setting's routine, among other factors). We have demonstrated that this routine placement effect is significant when learning a new flossing habit. (Judah, Gardner-Sood, \& Aunger, 2012)

Since the Evo-Eco approach has been shown to change behaviour in public health projects, and to inspire new empirical hypotheses about constraints on behaviour change in real world contexts, we hope this evidence - of both theoretical and empirical strength - provides sufficient grounds for the Evo-Eco approach to be used by public health workers and (social) marketers to devise more effective campaigns, by policy-makers to improve general well-being, and by the general public as inspiration for their own self-help projects.

\section{Acknowledgements}

Thanks to Adam Biran, Valerie Curtis, Micheal de Barra, Katie Greenland, Sharon Guten, Gaby Judah, Hans-Joachim Mosler, Helen Trevaskis, Robert West and Allan Wicker for reading earlier versions 


\section{References}

Abramson, C. (1994). A Primer of Invertebrate Learning: The Behavioral Perspective. Washington, DC: American Psychological Association.

Ajzen, I., \& Fishbein, M. (1980). Understanding Attitudes and Predicting Social Behavior. Englewood Cliffs, NJ: Prentice-Hall.

Armitage, C. J., \& Conner, M. (2001). Efficacy of the Theory of Planned Behaviour: a metaanalytic review. British Journal of Social Psychology, 40, 471-499.

Atran, S. (1998). Folk biology and the anthropology of science: Cognitive universals and cultural particulars. Behavioral and Brain Sciences, 21(4), 547-569.

Aunger, R. (2007). Toothbrushing as routine behaviour. International Dental Journal, 57, 364-376.

Aunger, R. (2010b). Types of technology. Technological Forecasting and Social Change, 77, 762782.

Aunger, R., \& Curtis, V. (accepted). Gaining Control: Major Transitions in the Evolution of Human Behaviour. Oxford: Oxford University Press.

Aunger, R., \& Curtis, V. (submitted). The 'Evolutionary-Ecological' Approach to Human Motivation. Behavioral and Brain Sciences.

Baars, B. (1997). In the Theater of Consciousness: The Workspace of the Mind. New York: Oxford University Press.

Badre, D., \& Frank, M. (2012). Mechanisms of hierarchical reinforcement learning in cortico-striatal circuits 2: evidence from FMRI. Cereb Cortex, 22(3), 527-536.

Balleine, B. W., \& Dickinson, A. (1998). Goal-directed instrumental action: Contingency and incentive learning and their cortical substrates. Neuropharmacology, 37, 407-419.

Balleine, B. W., \& O'Dohety, J. P. (2010). Human and rodent homologies in action control: corticostriatal determinants of goal-directed and habitual action. Neuropsychopharmacology, 35, 48-69.

Bar, M. (2007). The proactive brain: using analogies and associations to generate predictions. Trends in Cognitive Sciences, 11(7), 280-289.

Barker, R. G. (1968). Ecological Psychology: Concepts and methods for studying the environment of human behavior. Palo Alto, CA: Stanford University Press.

Barker, R. G. (1987). Prospecting in environmental psychology. In D. Stokols \& I. Altman (Eds.), Handbook of environmental psychology, Vol. 2. (pp. 1413-1432). New York: Wiley.

Barker, R. G., \& Schoggen, P. (1973). Qualities of Community Life: Methods of measuring environment and behavior applied to an American and an English town. San Francisco: Jossey-Bass.

Barker, R. G., \& Wright, H. F. (1954). Midwest and its Children: The Psychological Ecology of an American Town. Evanston, III: Row, Peterson and Company.

Barlow, G. (1977). Modal action patterns. In G. Barlow \& T. Sebeok (Eds.), How animals communicate (pp. 98-134). Bloomington, IN: Indiana University Press.

Barrett, L. (2011). Beyond the Brain: How Body and Environment Shape Animal and Human Minds. Princeton: Princeton University Press.

Barto, A. G., \& Mahadevan, S. (2003). Recent advances in hierarchical reinforcement learning. Discrete Event Dynamic Systems: Theory and Applications, 13, 343-379.

Baumeister, R. F., \& Tierney, J. (2012). Willpower: Rediscovering the Greatest Human Strength. London: Penguin Press.

Baumeister, R. F., Vohs, K. D., \& Funder, D. C. (2007). Psychology as the science of self-reports and finger movements: Whatever happened to actual behavior? Perspectives on Psychological Science, 2(4), 396-403.

Becker, M., Drachman, R., \& Kirscht, J. (1974). A new approach to explaining sick-role behavior in low-income populations. American Journal of Public Health, 64, 1062. 
Berridge, K. C., \& Robinson, T. E. (2003). Parsing reward. Trends in Neurosciences, 26, 507-513.

Best, J. A., \& Hakstian, A. R. (1978). A situation-specific model of smoking behavior. Addictive Behaviors, 3, 79-92.

Biran, A., Schmidt, W.-P., Rajaraman, D., Sanker, Greenland, K., Aunger, R., . . Curtis, V. (submitted). A randomized, controlled intervention trial of a village-level intervention to promote handwashing with soap in rural Indian households.

Boehm, C. (1999). Hierarchy in the Forest: The Evolution of Egalitarian Behavior. Cambridge, MA: Harvard University Press.

Botvinick, M. M. (2008). Hierarchical models of behavior and prefrontal function. Trends in Cognitive Sciences, 12, 201-208.

Botvinick, M. M., Niv, Y., \& Barto, A. C. (2009). Hierarchically organized behavior and its neural foundations: a reinforcement learning perspective. Cognition, 113, 262-280.

Boyer, P., \& Lienard, P. (2006). Why Ritualized Behavior? Precaution Systems and Action-Parsing in Developmental, Pathological and Cultural Rituals. Behavioral and Brain Sciences, 29, 1-56.

Breland, K., \& Breland, M. (1961). The misbehavior of organisms. American Psychologist, 16(11), 681.

Bubic, A., Von Cramon, D. Y., \& Schubotz, R. I. (2010). Prediction, cognition and the brain. Frontiers in Human Neuroscience, 4.

Bullemer, P., Nissen, M., \& Willingham, D. B. (1989). On the Development of Procedural Knowledge. Journal of Experiemental Psychology: Learning, Memory and Cognition, 15, 1047-1060.

Burghardt, G. M. (2005). The Genesis of Animal Play. Cambridge, MA: MIT Press.

Burke, A., Heuer, F., \& Reisberg, D. (1992). Remembering emotional events. Memory \& Cognition, 20, 277-290.

Butler, A. B. (2001). Brain evolution and comparative neuroanatomy Encyclopedia of the Life Sciences (pp. 1-8). London: Macmillan Publishers.

Caporael, L. R. (2003). Repeated assembly. In S. Schur \& F. Rauscher (Eds.), Alternative approaches to evolutionary psychology (pp. 71-90). New York: Kluwer.

Carver, C. S., \& Scheier, M. F. (1998). On the Self-regulation of Behavior. New York: Cambridge University Press.

Churchland, P., \& Sejnowski, T. J. (1992). The Computational Brain. Boston, MA: MIT Press.

Clark, A. (1997). Being There: Putting Brain Body and World Together Again. Cambridge, MA: MIT Press.

Coleman, J. (1990). Foundations of Social Theory. Cambridge, MA: Belknap Press.

Curtis, V., \& Aunger, R. (2011). Motivational mismatch: Evolved motives as the source of - and solution to - global public health problems. In S. C. Roberts (Ed.), Applied Evolutionary Psychology (pp. 259-275). Oxford: Oxford University Press.

Daw, N. D., Gershman, S. J., Seymour, B., Dayan, P., \& Dolan, R. J. (2011). Model-based influences on humans' choices and striatal prediction errors. Neuron, 69(6), 1204-1215.

Daw, N. D., Niv, Y., \& Dayan, P. (2005). Uncertainty-based competition between prefrontal and dorsolateral striatal systems for behavioral control. Nature Neuroscience, 8, 1704-1711.

Daw, N. D., \& Shohamy, D. (2008). The cognitive neuroscience of motivation and learning. Social Cognition, 26(5), 593-620.

Dayan, P., \& Niv, Y. (2008). Reinforcement learning: the good, the bad and the ugly. Current Opinion in Neurobiology, 18(2), 185-196.

Dayan, P., Niv, Y., Seymour, B., \& D Daw, N. (2006). The misbehavior of value and the discipline of the will. Neural Networks, 19(8), 1153-1160.

Dennett, D. (1995). Darwin's dangerous idea: evolution and the meanings of life. London: Penguin. 
Dickinson, A. (1985). Actions and habits: the development of behavioral autonomy. Phil Trans $R$ Soc $B, 308,67-78$.

Dickinson, A., \& Balleine, B. (2002). The role of learning in the operation of motivational systems. In H. Pashler \& R. Gallistel (Eds.), Stevens' Handbook of Experimental Psychology, Third Edition (Vol. 3. Learning, Motivation, and Emotion, pp. 497-534). New York: John Wiley \& Sons.

Dietterich, T. G. (2000). Hierarchical reinforcement learning with the MAXQ value function decomposition. Journal of Artificial Intelligence Research, 13, 227-303.

Dooris, M. (2009). Holistic and sustainable health improvement: the contribution of the settingsbased approach to health promotion

January:,.. Perspectives in Public Health, 129, 29-36.

Doya, K. (2007). Bayesian brain: Probabilistic approaches to neural coding: MIT Press.

Eichenbaum, H. (2000). Declarative memory. Nature Reviews Neuroscience, 1, 41-50

Eilam, D., Zor, R., Szechtman, H., \& Hermesh, H. (2006). Ritual, stereotypy and compulsive behavior in animals and humans. Neuroscience and Biobehavioral Reviews, 30, 456-471.

Everitt, B. J., \& Robbins, T. W. (2005). Neural systems of reinforcement for drug addiction: From actions to habits to compulsion. Nature Neuroscience, 8, 1481-1489.

Fernando, C., Szathmáry, E., \& Husbands, P. (2012). Selectionist and evolutionary approaches to brain function: a critical appraisal. Frontiers in Computational Neuroscience, 6.

Fishbein, M. (2008). A reasoned action approach to health promotion. Medical Decision Making, $28,834-844$.

Fishbein, M., \& Ajzen, I. (2010). Predicting and changing behavior: The reasoned action approach. New York: Psychology Press.

Fishbein, M., Triandis, H., \& Kanfer, F. (2001). Factors influencing behaviour and behaviour change. In B. A, R. TA \& S. JE (Eds.), Handbook of Health Psychology (pp. 3-17). Mahwah, NJ: Lawrence Erlbaum Associates.

Flay, B., \& Petraitis, J. (1994). The theory of triadic influence. Advances in Medical Sociology, 1944.

Flay, B. R., Snyder, F., \& Petraitis, J. (2009). The Theory of Triadic Influence. In R. J. DiClemente, M. C. Kegler \& R. A. Crosby (Eds.), Emerging Theories in Health Promotion Practice and Research. Second ed. (pp. 451-510). New York: Jossey-Bass.

Fox, R. (1984). Kinship and Marriage: An Anthropological Perspective. Cambridge: Cambridge University Press.

Freeman, W. J. (1999). How the Brain Makes up its Mind. London: Weidenfeld and Nicholson.

Friston, K. (2010). The free-energy principle: A unified brain theory? Nature Reviews Neuroscience, 11, 127-138.

Friston, K. J., \& Stephan, K. E. (2007). Free-energy and the brain. Synthese, 159(3), 417-458.

Gallagher, S. (2005). How the body shapes the mind: Cambridge Univ Press.

Garcia, J., \& Koelling, R. (1966). Relation of cue to consequence in avoidance learning. Psychonomic Science, 4, 123-124.

Geary, D. C., \& Flinn, M. V. (2001). Evolution of human parental behavior and the human family. Parenting: Science and Practice, 1, 5-61.

Gershman, S. J., Pesaran, B., \& Daw, N. D. (2009). Human reinforcement learning subdivides structured action spaces by learning effector-specific values. The Journal of Neuroscience, 29(43), 13524-13531.

Gibson, J. J. (1979). The Ecological Approach to Visual Perception. Boston: Houghton-Mifflin.

Glenberg, A. M. (2010). Embodiment as a unifying perspective for psychology. Wiley Interdisciplinary Reviews: Cognitive Science, 1(4), 586-596.

Godfrey-Smith, P. (2007). Conditions for Evolution by Natural Selection. Journal of Philosophy, 104, 489-516. 
Grant, P. R., \& Grant, B. R. (2002). Unpredictable Evolution in a 30-Year Study of Darwin's Finches. Science, 296, 707-711.

Grassé, P.-P. (1959). La Reconstruction du nid et les Coordinations Inter-Individuelles chez Bellicositermes Natalensis et Cubitermes sp. La théorie de la Stigmergie: essai d'interpretation du Comportement des Termites Constructeurs. Insectes Sociaux, 6, 41-81.

Greif, M. L., Nelson, D. G. K., Keil, F. C., \& Gutierrez, F. (2006). What do children want to know about animals and artifacts? Domain-specific requests for information. Psychological Science, 17(6), 455-459.

Hawkins, J., \& Blakeslee, S. (2004). On Intelligence. New York: Henry Holt.

Hebb, D. O. (1949). The Organization of Behavior. New York: John Wiley and Sons.

Hirschfeld, L. (2001). On a folk theory of society: Children, evolution, and mental representations of social groups. Personality \& Social Psychology Review, 5, 107-117.

Huey, R., Hertz, P., \& Sinervo, B. (2003). Behavioral drive versus behavioral inertia in evolution: a null model approach. American Naturalist, 161, 357-366.

Hull, C. L. (1943). Principles of Behavior: An Introduction to Behavior Theory. New York: AppletonCentury Co.

Hutchins, E. (1995). Cognition in the Wild. Cambridge MA: MIT Press.

Hutchinson, G. E. (1957). Concluding remarks. Cold Spring Harbor Symposia on Quantitative Biology, 22, 415-427.

Inagaki, K., \& Hatano, G. (2006). Young children's conception of the biological world. Current Directions in Psychological Science, 15(4), 177-181.

James, W. (1884). What is an emotion? Mind, 19, 188-204.

Joe, W. Q., Ferraro, M., \& Schwartz, M. F. (2002). Sequencing and interleaving in routine action production. Neurocase, 8(1-2), 135-150.

Judah, G., Gardner-Sood, B., \& Aunger, R. (2012). Forming a Flossing Habit: An Investigation into the Psychological Determinants of Habit Formation. British Journal of Health Psychology.

Kensinger, E., \& Corkin, S. (2004). Two routes to emotional memory: Distinct neural processes for valence and arousal. Proceedings of the National Academy of Sciences USA, 101, 33103315.

Kopp, B. (2012). A simple hypothesis of executive function. Frontiers of Human Neuroscience, 6 , 159.

Kotler, P., Roberto, N., \& Lee, N. R. (2002). Social Marketing: Improving the Quality of Life. 2nd ed. New York: Sage.

Krasne, F. B., \& Glanzman, D. L. (1995). What we can learn from invertebrate learning. Annual Review of Psychology, 46, 585-624.

Krebs, J. R., \& Dawkins, R. (1978). Animal signals: Mind reading and manipulation. In J. R. Krebs \& N. B. Davies (Eds.), Behaviour Ecology: An Evolutionary Approach (pp. 380-402). Sunderland, MA: Sinauer Associates.

Kuba, M., Meisel, D. V., Byrne, R. A., Griebel, U., \& Mather, J. A. (2003). Looking at play in Octopus vulgaris. Berliner Paläobiol. Abh., 3, 163-169.

Lally, P., Jaarsveld, C. H. M. V., Potts, H. W. W., \& Wardle, J. (2009). How are habits formed: Modelling habit formation in the real world. European Journal of Social Psychology, DOI: 10.1002/ejsp.674.

Lewontin, R. C. (1970). The Units of Selection. Annual Review of Ecology and Systematics, 1, $1-$ 18.

Llinas, R. (2002). I of the Vortex: From Neurons to Self. Cambridge, MA: MIT Press.

Lorenz, K. (1950). The comparative method in studying innate behaviour patterns. In J. F. Danielli \& R. Brown (Eds.), Physiological Mechanisms in Animal Behaviour. Cambridge:

Cambridge University Press.

Mackintosh, N. J. (1985). Conditioning and Associative Learning. Oxford: Oxford University Press. 
Martin, G., \& Pear, J. (2007). Behavior modification: What it is and how to do it. 8th ed. . Upper Saddle River, NJ: Pearson Prentice Hall.

Martínez - Meyer, E., Townsend Peterson, A., \& Hargrove, W. W. (2004). Ecological niches as stable distributional constraints on mammal species, with implications for Pleistocene extinctions and climate change projections for biodiversity. Global Ecology and Biogeography, 13(4), 305-314.

Mather, J. A., \& Anderson, R. C. (1999). Exploration, play and habituation in Octopus dofleini. Journal of Comparative Psychology, 113, 333-338.

Maynard Smith, J., \& Harper, D. (2003). Animal Signals. Oxford: Oxford University Press.

McDowell, J. J. (2010). Behavioral and neural Darwinism: Selectionist function and mechanism in adaptive behavior dynamics. Behavioural Processes, 84, 358-365.

McKenzie-Mohr, D., \& Smith, W. (2000). Fostering Sustainable Behaviour: An Introduction to Community-based Social Marketing. Gabriola Island: New Society Publishers.

Medin, D., \& Atran, S. (1998). Folk Biology. Cambridge, MA: MIT Press.

Michalak, J., Troje, N. F., Fischer, J., Vollmar, P., Heidenreich, T., \& Schulte, D. (2009). Embodiment of sadness and depression-gait patterns associated with dysphoric mood. Psychosomatic Medicine, 71(5), 580-587.

Millikan, R. G. (2000). On Clear and Confused Ideas: An Essay about Substance Concepts. Cambridge: Cambridge University Press.

Mitani, J. C., Call, J., Kappeler, P. M., Palombit, R. A., \& Silk, J. B. (2012). The Evolution of Primate Societies. Chicago: University Of Chicago Press.

Mittal, B. (1988). Achieving higher seat belt usage: The role of habit in bridging the attitudebehavior gap. Journal of Applied Social Psychology, 18, 993-1016.

Montague, P. R., \& Berns, G. S. (2002). Neural economics and the biological substrates of valuation. Neuron, 36, 265-284.

Moriarty, D. E., Schultz, A. C., \& Grefenstette, J. J. (1999). Evolutionary algorithms for reinforcement learning. Journal of Artificial Intelligence Research 11, 241-276.

Morrison, V., \& Bennett, P. (2009). An Introduction to Health Psychology. 2nd ed. Harlow, UK: Pearson Education.

Neal, D. T., Wood, W., Labrecque, J. S., \& Lally, P. (2012). How do habits guide behavior? Perceived and actual triggers of habits in daily life. Journal of Experimental Social Psychology, 48, 492-498.

Northcutt, R. G., \& Kaas, J. H. (1995). The emergence and evolution of mammalian neocortex. Trends in the Neurosciences, 18, 373-379.

Odling-Smee, F. J., Laland, K. N., \& Feldman, M. (2003). Niche Construction: The Neglected Process in Evolution. Princeton: Princeton University Press.

Orians, G., \& Heerwagen, J. H. (1992). Evolved responses to landscapes. In J. H. Barkow, L. Cosmides \& J. Tooby (Eds.), The Adapted Mind (pp. 555-580). Oxford: Oxford University Press.

Ostlund, S. B., Winterbauer, N. E., \& Balleine, B. W. (2009). Evidence of Action Sequence Chunking in Goal-Directed Instrumental Conditioning and Its Dependence on the Dorsomedial Prefrontal Cortex. The Journal of Neuroscience, 29, 8280-8287.

Ouellette, J., \& Wood, W. (1998). Habit and intention in everyday life: The multiple processes by which past behavior predicts future behavior. Psychological Bulletin, 124, 54-74.

Owen, N., Humpel, N., Leslie, E., Bauman, A., \& Sallis, J. F. (2004). Understanding Environmental Influences on Walking: Review and Research Agenda. American Journal of Preventive Medicine, 27, 67-76.

Parr, R., \& Russell, S. (1998). Reinforcement learning with hierarchies of machines. Advances in Neural Information Processing Systems, 10, 1043-1049. 
Pasupathy, A., \& Miller, E. K. (2005). Different time courses of learning-related activity in the prefrontal cortex and striatum. Nature, 433, 873-876.

Pavlov, I. (1927). Conditioned Reflexes: An Investigation of the Physiological Activity of the Cerebral Cortex. London: Routledge and Kegan Paul.

Pinker, S. (1994). The language instinct. London: Allen Lane.

Plotkin, H. (1988). Learning and evolution. In H. Plotkin (Ed.), The role of behavior in evolution. Cambridge: MIT Press.

Poldrack, R. A., Sabb, F. W., Foerde, K., Tom, S. M., Asarnow, R. F., Bookheimer, S. Y., \& Knowlton, B. J. (2005). The neural correlates of motor skill automaticity. Journal of Neuroscience, 25, 5356-5364.

Potts, R. (2012). Evolution and Environmental Change in Early Human Prehistory. Annual Review of Anthropology, 41, 151-167.

Povinelli, D. J. (2000). Folk Physics for Apes: The Chimpanzee's Theory of How the World Works Oxford: Oxford University Press.

Prochaska, J., \& DiClemente, C. (1983). Stages and processes of self-change of smoking: Toward an integrative model of change. Journal of Consulting and Clinical Psychology, 51, 390395.

Quartz, S. (2001). Toward a developmental evolutionary psychology: Genes, development, and the evolution of human cognitive architecture. In S. Scher, M. Rauscher \& (Eds). (Eds.), Evolutionary Psychology: Alternative approaches: Kluwer.

Rao, R. P., \& Ballard, D. H. (1999). Predictive coding in the visual cortex: a functional interpretation of some extra-classical receptive-field effects. Nature Neuroscience, 2(1), 79-87.

Ravenscroft, I. (2010). Folk Psychology as a Theory. Stanford Encyclopedia of Philosophy.

Redish, A. D. (2013). The Mind within the Brain: How we make decisions and how those decisions go wrong. Oxford: Oxford University Press.

Rescorla, R. A., \& Wagner, A. R. (1972). A theory of Pavlovian conditioning: variations in the effectiveness of reinforcement and nonreinforcement. In A. Black \& W. Prokasy (Eds.), Classical conditioning II: current research and theory (pp. 64-69). New York: AppletonCentury-Crofts.

Ribas-Fernandes, J., Solway, A., Diuk, C., McGuire, J., Barto, A., Niv, Y., \& Botvinick, M. (2011). A neural signature of hierarchical reinforcement learning. Neuron, 71, 370-379.

Richerson, P. J., \& Boyd, R. (2005). Not by Genes Alone: How Culture Transformed Human Evolution. Chicago, IL: University of Chicago Press.

Riker, W. H., \& Ordeshook, P. C. (1973). An Introduction to Positive Political Theory. Englewood Cliffs: Prentice-Hall.

Rogers, E. (1995). Diffusion of Innovations. 4th ed. New York, NY: The Free Press.

Rolls, E. T. (1999). The Brain and Emotion. Oxford: Oxford University Press.

Rolls, E. T. (2005). Emotion Explained. Oxford: Oxford University Press.

Sallis, J. F., Cervero, R. B., Ascher, W., Henderson, K. A., Kraft, M. K., \& Kerr, J. (2006). An ecological approach to creating active living communities. Annual Review of Public Health, 27, 297-322.

Schank, R., \& Abelson, R. (1977). Scripts, Plans Goals and Understanding: An Inquiry Into Human Knowledge Structures. Hillsdale, NJ: Erlbaum.

Schoggen, M., Barker, L. S., \& Barker, R. G. (1963). Structure of the Behavior of American and English Children. In R. G. Barker (Ed.), The stream of behavior: Explorations of its structure \& content (pp. 160-168). East Norwalk, CT: Appleton-Century-Crofts.

Schoggen, P. (1989). Behaviour Settings: A Revision and Extension of Roger G. Barker's Ecological Psychology. Stanford, CA: Stanford University Press.

Schultz, W. (2000). Multiple reward signals in the brain. Nature Reviews Neuroscience, 1, 199-206. 
Schwarzer, R. (2008). Modeling health behavior change: How to predict and modify the adoption and maintenance of health behaviors. Applied Psychology: An International Review, 57, $1-29$.

Serruya, D., \& Eilam, D. (1996). Stereotypies, compulsions, and normal behavior in the context of motor routines in the rock hyrax (Procavia capensis). Psychobiology, 24, 235-246.

Shadmehr, R., Smith, M. A., \& Krakauer, J. W. (2010). Error correction, sensory prediction, and adaptation in motor control. Annual Review of Neuroscience, 33, 89-108.

Simon, H. (1974). How Big is a Chunk? Science, 183, 482-488.

Singh, S., Lewis, R. L., Barto, A. G., \& Sorg, J. (2010). Intrinsically Motivated Reinforcement Learning: An Evolutionary Perspective. IEEE Transactions on Autonomous Mental Development (IEEE TAMD), 2, 70-82.

Squire, L. R. (2004). Memory systems of the brain: A brief history and current perspective. Neurobiology of Learning and Memory, 82, 171-177.

Staddon, J. E. R. (2003). Adapative Behavior and Learning (2nd electronic ed) Retrieved from http://psychweb.psych.duke.edu/department/jers/abl/TableC.htm

Sterelny, K. (2003). Mind in a Hostile World. Oxford: Oxford University Press.

Stokols, D. (1992). Establishing and maintaining healthy environments: Toward a social ecology of health promotion. American Psychologist, 47, 6-22.

Stokols, D. (1995). The paradox of environmental psychology. American Psychologist, 50, 821837.

Streidter, G. F. (2005). The Principles of Brain Evolution. Sunderland, MA: Sinauer Associates.

Sutton, R. S. (1984). Temporal credit assignment in reinforcement learning. (Doctor of Philosophy), University of Massachusetts at Amherst.

Sutton, R. S. (2009). Deconstructing Reinforcement Learning. Paper presented at the 26th International Conference on Machine Learning (ICML), Montreal.

Sutton, R. S., \& Barto, A. G. (1998). Reinforcement Learning: An Introduction. Cambridge, MA: MIT Press.

Sutton, R. S., Precup, D., \& Singh, S. (1999). Between MDPs and semi-MDPs: A Framework for Temporal Abstraction in Reinforcement Learning. Artificial Intelligence, 112, 181-211.

Sutton, S. (2000a). A critical review of the transtheoretical model applied to smoking cessation. In P. Norman, C. Abraham \& M. Conner (Eds.), Understanding and Changing Health Behaviour : from Health Beliefs to Self-Regulation (pp. 207-225). Amsterdam: Harwood Academic.

Swanson, L. W. (2003). Brain Architecture: Understanding the Basic Plan. Oxford: Oxford University Press.

Talmi, D., Seymour, B., Dayan, P., \& Dolan, R. J. (2008). Human pavlovian-instrumental transfer. The Journal of Neuroscience, 28(2), 360-368.

Terrace, H. S. (2001). Chunking and serially organized behavior in pigeons, monkeys and humans. In R. G. Cook (Ed.), Avian Visual Cognition. Medford, MA: Comparative Cognition Press.

Thorndike, E. L. (1901). Animal intelligence: An eperimental study of the associative processes in animals. Psychological Review Monograph Supplement, 2, 1-109.

Tinbergen, N. (1963). On aims and methods of ethology. Zeitschrift für Tierpsychologie, 20, 410433.

Tolman, E. (1948). Cognitive maps in rats and men. Psychology Review, 55, 189-208.

Tulving, E. (1985). How many memory systems are there? American Psychologist, 40, 385-398.

Ulam, P., \& Balch, T. (200?). Niche selection for foraging tasks in multi-robot teams using reinforcement learning.

Valentin, V. V., Dickinson, A., \& O'Doherty, J. P. (2007). Determining the neural substrates of goal-directed learning in the human brain. Journal of Neuroscience, 27, 4019-4026. 
von Neumann, J., \& Morgenstern, O. (1944). Theory of Games and Economic Behavior. Princeton: Princeton University Press.

Waelti, P., Dickinson, A., \& Schultz, W. (2001). Dopamine responses comply with basic assumptions of formal learning theory. Nature, 412, 43-48.

Wcislo, W. (1989). Behavioral environments and evolutionary change. Annu Rev Ecol Syst, 20, 137-169.

West, R. (2005). Time for a change: putting the Transtheoretical (Stages of Change) Model to rest. What Does it Take for a Theory to be Abandoned? The Transtheoretical Model of Behaviour Change as a Test Case. Addiction, 100, 1048-1050.

Whitelaw, S., Baxendale, A., Bryce, C., MacHardy, L., I, Y., \& Witney, E. (2001). 'Settings' based health promotion: a review. Health Promotion International, 16, 339-353.

Whiteson, S., \& Stone, P. (2006). Evolutionary function approximation for reinforcement learning. Journal of Machine Learning Research, 7, 877-917.

Wilkinson, R. G. (2005). The Impact of Inequality: How to Make Sick Societies Healthier. London: Routledge.

Willis, W. D. (1985). The Pain System: The Neural Basis of Nociceptive Transmission in the Mammalian Nervous System. Basel: Kragel.

Wunderlich, K., Dayan, P., \& Dolan, R. J. (2012). Mapping value based planning and extensively trained choice in the human brain. Nature Neuroscience.

Wyles, J., Kunkel, J., \& Wilson, A. (1983). Birds, behavior, and anatomical evolution. Proc Natl Acad Sci USA, 80, 4394-4397.

Yerkes, R. M., \& Dodson, J. D. (1908). The relation of strength of stimulus to rapidity of habitformation. Journal of Comparative Neurology and Psychology, 18, 459-482.

Yin, H. H., \& Knowlton, B. J. (2006). The role of the basal ganglia in habit formation. Nature Neuroscience, 7, 464-476.

Young, M. (1988). The Metronomic Society: Natural Rhythms and Human Timetables. Cambridge, MA: Harvard University Press.

Zacks, J. M., \& Tversky, B. (2001). Event structure in perception and conception. Psychological Bulletin, 127, 3-21. 


\section{Footnotes}

1 That is, it refers to stimulus-response or stimulus-response-outcome rather than stimulusstimulus association learning.

2 Basic reinforcement learning models make learning and memory equivalent to the act of perceiving new states of the world; here we distinguish two separate steps: perception of the consequences of behaviour, and the mental processes of making inferences from what is perceived (learning) and then storage of those inferences (memory). This is closer in psychological terms to what happens in brains.

3 The Evo-Eco Process Model is not a psychological model in the sense of including extensive predictions about information processing in the brain - that is, it does not specify particular relationships between mental constructs as can be seen, e.g., in the Health Belief Model (Becker, Drachman, \& Kirscht, 1974), or expectancy-value approaches such as the Theory of Planned Behaviour (Ajzen \& Fishbein, 1980). This is because the model is couched at a higher level of abstraction, including many different kinds of causal factors than just cognitive ones. We don't believe this to be a liability, but rather a strength, as it is much more likely that the important causes of behaviour will be discovered by a broader search through the kinds of factors we emphasize.

4 The Evo-Eco approach differs from Self-Regulation and the ABC approach by being more specific to behaviour; these two approaches are general cybernetic models that hold for any homeostatic process, whether physical, biological or social (i.e., they are equally applicable to the description of responses by thermostats to external temperature change, animals to changed environments or population sizes to ecological constraints). The Evo-Eco approach differs from the Transtheoretical ('Stages of Change') approach in not being a stage model with little empirical support for the stages or processes specified. (S. Sutton, 2000a; West, 2005)

5 What happens inside a computer can also be described using Newtonian principles, although it might require quite a long description.

6 There are some limnal objects or states of being: artificially intelligent objects, capable of a strategic response, but without genes, lie between the biological and physical environments. Dead animals and people can probably be considered to form part of the physical environment, as their genes are no longer active or relevant and these objects don't strategize any longer.

7 They don't, however, make manipulable objects - with the exception of a few spiders, which make webs that they can maneuver about with their legs.

${ }^{8}$ Here, I exclude the complex dwelling creation conducted by social insects such as termites, which create large structures using a particular kind of rigid mechanism (stigmergy), (Grassé, 1959) or the transformation of soil layers by earthworms through continual digestion of their surroundings. These mechanisms are unlike the highly creative production process used by humans.

${ }^{9}$ Existing theories of behaviour change such as Self-Regulation theory, the ABC approach and the Transtheoretical Model do not recognize the impact of one behaviour on another. They think of 
behaviour in abstract terms, such as stopping smoking or eating a healthy diet - behaviours which are obviously complex in many ways, including temporally.

10 This argument for evolutionary precursors to human forms of behaviour settings is novel here; it is not characteristic of the 'Barker school' in ecological psychology, where the concept of a behaviour setting originated. Placing the notion of a behaviour setting into this evolutionary framework makes it closer to Caporael's 'repeated assembly' concept (Caporael, 2003), which involves organisms, artifacts and practices being repeatedly put together for interaction as a unit of natural selection. Repeated assemblies are 'recurrent entity-environment relations composed of hierarchically organized heterogeneous components having different temporal frequencies and scales of replication'. Thus, although more general (genes are taken as an example), this concept should include behaviour settings as an example.

${ }^{11}$ A related notion is that of 'affordance', associated with Gibson. (Gibson, 1979) However, it is not as specific, nor part of as powerful an 'ecology of ideas', as developed by the Barker school.

12 It is important to note that this level of organization occurs between the individual and the usual social scientific concept of an organization, such as a business or school. In particular, multiple settings can occur within the operation of a social organization (e.g., 'Mrs. Smith's music class' within a school, or 'weekly staff meeting' within a government bureau). This makes Barker's notion of a setting different from the setting concept used in health promotion, or the WHO's 'healthy setting' concept, which equate a setting with a hospital, village or other social organization. (Dooris, 2009; Whitelaw et al., 2001) When necessary, the phrase 'behaviour setting' will be utilized to ensure the ecological psychological notion is distinguished from this other use.

${ }^{13}$ We exclude further consideration of the content of interventions as being a matter specific to particular behaviour change programs, and not much subject to scientific analysis.

14 Reflexive actions could be chained together by natural selection over generations to produce complex behaviour sequences such as the closing up of larval cells in honeycomb by bees, but these were controlled in primitive fashion: each completed action was taken as a cue for the next. (Tinbergen, 1963)

15 'Lack of uptake' behaviours have been called 'health-enhancing' or 'health-protective' and 'super-stimulating' behaviours 'health-risk' or 'health compromising' by health psychologists (with a further category of 'health inequalities' due to social inequality) (B. Flay \& Petraitis, 1994; Morrison \& Bennett, 2009), albeit without the same theoretical underpinnings as provided here.

16 People may also not take up new technologies because they do not have access to them. This can occur when people live in the 'ancestral state' of pre-industrial lifestyles where the primary causes of early death are violence and pathogens. Lack of uptake in these cases has become a 'problem' because the modern world has introduced new solutions which relatively poor people are not in position to adopt.

${ }_{17}$ A number of caveats should be noted here. Many factors can come into play before a learning problem becomes a public health problem: many people must exhibit the learning deficit, the environment must be characterized in specific way for the learning problem to arise and persist (foiling the evolutionary 'tinkering' of learning mechanisms), the learning deficit must relate to a significant health outcome, a tenable solution must be evident (or the 'problem' simply has no 
'solution'), and social institutions must recognize the problem as a problem. Also, admittedly, behaviour is only one aspect of these problems: for example, the AIDS epidemic is also caused by challenges to the human immune system presented by a fast-evolving, virulent virus, and undernutrition by geopolitical and economic inequalities. Further, in some cases, a public health intervention need not require behaviour change at all. For example, iodine was introduced into salt in some countries by governmental decree, producing health benefits for the population, but without requiring people to engage in any novel behaviour, nor to stop doing anything in particular, but simply to continue consuming salt. Nevertheless, we have shown there is a common link among all major global public health problems, which is that the behavioural underpinnings - such as inadequate uptake of condoms or adherence to anti-retroviral therapy in the case of AIDS - can be explained as a kind of inappropriate or unfortunate learning, and that there are strong linkages between these learning difficulties, behavioural problems, risk factors and public health issues.

18 However, this advice has partly grown from studies using one of the health psychological approaches which is not based on expectancy-value, the Transtheoretical model, (Prochaska \& DiClemente, 1983) which is processual in nature, but still would not identify many of the factors mentioned in the advice explicitly.

${ }^{19}$ Evolution has been called the most powerful idea ever, a 'universal acid' for solving problems. (Dennett, 1995) Although both utility theory and evolutionary biology are functionalist, biology has the edge in supplying us with content about what we should value. The expected utility concept is agnostic about what things can hold utility for people, while the concept of adaptation in evolutionary biology can be used to elucidate what kinds of behavioural outcomes promote wellbeing (through survival and reproduction).

${ }^{20}$ A few alternative models are available, primarily the Social Ecology approach, (Stokols, 1992) Diffusion of Innovations model, (Rogers, 1995) Transtheoretical approach, (Prochaska \& DiClemente, 1983) and Social Marketing approach, (Kotler, Roberto, \& Lee, 2002) but each of these occupies a small, specialized niche in the practical world of behaviour change programs.

${ }^{21}$ Even a recent effort to broaden consideration of the influences on behaviour by taking a 'metatheoretical' approach, the Triadic Influence approach (B. R. Flay, Snyder, \& Petraitis, 2009), winds up arguing that all of the new influences (genetic, cultural and social environment, personal traits) work through the normal expectancy-value factors (e.g., attitudes, self-efficacy and intention) in a proximal sense to cause behaviour. So practictioners can still get away with measuring just the same set of factors as before when using this approach.

22 Fishbein's 'Integrative Model of Behaviour Prediction' (M. Fishbein, 2008) does admit that, in an unspecified way, the environment can directly hinder or facilitate behaviour; such constraints are argued to be the reason why intention does not always fully explain action. 